NBER WORKING PAPER SERIES

\title{
MONETARY POLICY UNDER UNCERTAINTY IN MICRO-FOUNDED MACROECONOMETRIC MODELS
}

\author{
Andrew T. Levin \\ Alexei Onatski \\ John C. Williams \\ Noah Williams \\ Working Paper 11523 \\ http://www.nber.org/papers/w11523
NATIONAL BUREAU OF ECONOMIC RESEARCH 1050 Massachusetts Avenue
Cambridge, MA 02138
July 2005

The views expressed herein are solely the responsibility of the authors and should not be interpreted as reflecting the views of the Board of Governors of the Federal Reserve System, the management of the Federal Reserve Bank of San Francisco, or anyone else associated with the Federal Reserve System. We appreciate comments and suggestions from the editors, Mark Gertler and Ken Rogoff, and from our two discussants, Giorgio Primiceri and Carl Walsh. This paper has also benefitted from conversations with Klaus Adam, Michele Cavallo, Steve Cecchetti, Matt Canzoneri, Richard Dennis, Behzad Diba, John Fernald, John Leahy, David Lopez-Salido, and Lars Svensson. The views expressed herein are those of the author(s) and do not necessarily reflect the views of the National Bureau of Economic Research.

(C)2005 by Andrew T. Levin, Alexei Onatski, John C. Williams and Noah Williams. All rights reserved. Short sections of text, not to exceed two paragraphs, may be quoted without explicit permission provided that full credit, including (C) notice, is given to the source. 
Monetary Policy Under Uncertainty in Micro-Founded Macroeconometric Models Andrew T. Levin, Alexei Onatski, John C. Williams and Noah Williams

NBER Working Paper No. 11523

July 2005

JEL No. C11, C22, E31, E52, E61, E63

\section{ABSTRACT}

We use a micro-founded macroeconometric modeling framework to investigate the design of monetary policy when the central bank faces uncertainty about the true structure of the economy. We apply Bayesian methods to estimate the parameters of the baseline specification using postwar U.S. data, and then determine the policy under commitment that maximizes household welfare. We find that the performance of the optimal policy is closely matched by a simple operational rule that focuses solely on stabilizing nominal wage inflation. Furthermore, this simple wage stabilization rule is remarkably robust to uncertainty about the model parameters and to various assumptions regarding the nature and incidence of the innovations. However, the characteristics of optimal policy are very sensitive to the specification of the wage contracting mechanism, thereby highlighting the importance of additional research regarding the structure of labor markets and wage determination.

Andrew T. Levin

Federal Reserve Board

$20^{\text {th }}$ Street and Constitution Avenue NW

Washington, DC 20551

levina@frb.gov

Alexei Onatski

Department of Economics

Columbia University

$420 \mathrm{~W} 118^{\text {th }}$ Street

New York, NY 10027

ao2027@columbia.edu
John C. Williams

Federal Reserve Bank of San Francisco

101 Market Street

San Francisco, CA 94105

john.c.williams@sf.frb.org

Noah Williams

Department of Economics

001 Fisher Hall

Princeton University

Princeton, NJ 08544-1021

and NBER

noahw@princeton.edu 
Uncertainty is not just an important feature of the monetary policy landscape; it is the defining characteristic of that landscape.

Alan Greenspan (2003)

\section{Introduction}

Eight years ago, two Macroeconomics Annual papers-Goodfriend and King (1997) and Rotemberg and Woodford (1997)-played a central role in stimulating a burgeoning research program regarding the monetary policy implications of macroeconomic models with explicit microeconomic foundations. ${ }^{1}$ This research program incorporates two crucial elements compared with more traditional monetary policy analysis. First, reflecting the influence of the Lucas (1976) critique, the emphasis on explicit microeconomic foundations is intended to ensure that the resulting structural equations are reasonably invariant to the choice of monetary policy. Second, this research follows the standard public finance approach of determining the policy regime that maximizes household welfare and then evaluating the performance of alternative policies relative to this benchmark.

After initially focusing on small stylized models, this line of research has subsequently proceeded to analyze micro-founded macroeconometric models that incorporate an expanded set of nominal and real rigidities and hence can be matched more closely to observed aggregate data. For example, Christiano, Eichenbaum, and Evans (2005) (henceforth CEE) specified a dynamic general equilibrium model with a number of distinct structural features: staggered wage and price setting with partial indexation; habit persistence in consumption; endogenous capital accumulation with higher-order adjustment costs; and variable capacity utilization. ${ }^{2}$ Smets and Wouters (2003a) (henceforth SW) later applied full-information

\footnotetext{
${ }^{1}$ Other early examples include Levin (1989), King and Wolman (1999), McCallum and Nelson (1999), and Rotemberg and Woodford (1999). For a thorough presentation of this approach as well as a comprehensive bibliography, see Woodford (2003).

${ }^{2}$ Christiano, Eichenbaum, and Evans (2005) also documented the importance of these structural features in generating a model-implied response to a monetary policy shock consistent with that of an identified vector autoregression (VAR). More recently, Altig, Christiano, Eichenbaum, and Linde (2004) have extended
} 
Bayesian methods to estimate essentially the same specification (augmented by a larger set of structural disturbances), and found that the model is competitive with an unrestricted Bayesian VAR in terms of goodness-of-fit and out-of-sample forecasting performance. ${ }^{3}$

In this paper, we investigate the design of monetary policy when the central bank faces uncertainty regarding the true structure of the economy. Of course, a long-established literature has considered this topic using traditional structural macroeconomic models, building on the seminal work of Brainard (1967). ${ }^{4}$ Nevertheless, recent analysis of small stylized microfounded models has demonstrated that the implications of uncertainty can be markedly different when the policymaker's goal is to maximize household welfare, because the welfare function itself depends on the specification and parameter values of the model. ${ }^{5}$

By using a micro-founded macroeconometric modeling framework, we can examine the policy implications of several aspects of uncertainty that may be more difficult to consider in a small stylized model. First, by applying Bayesian methods, we can use the posterior distribution of the model parameters to determine whether simple rules that perform well in the baseline economy are robust to parameter uncertainty, that is, to the range of parameter values that are reasonably consistent with the observed data. Second, we can gauge the degree of innovation uncertainty by evaluating the extent to which the policy conclusions are sensitive to alternative assumptions regarding the nature and incidence of the structural shocks to the model. Finally, we can explore the implications of specification uncertainty by changing specific features of the model such as the role of money balances or the structure

the model to incorporate firm-specific capital accumulation and have analyzed its behavior in response to productivity shocks, while Christiano, Motto, and Rostagno (2004) incorporate a banking system and capital market frictions in their study of the Great Depression.

${ }^{3}$ See also Smets and Wouters (2003b) as well as the papers cited in Section 3 below.

${ }^{4}$ See McCallum (1988), Craine (1979), Soderstrom (2002), Rudebusch (2001), Taylor (1999a), and Brock, Durlauf, and West (2003). Robust control methods have also been used in investigating monetary policy under uncertainty; see Hansen and Sargent (2003), Onatski and Stock (2002), Onatski (2000), Giannoni (2002), and Tetlow and von zur Muehlen (2002).

${ }^{5}$ See Levin and J. Williams (2004), Kimura and Kurozumi (2003), and Walsh (2005). 
of nominal contracts. ${ }^{6}$

As the baseline specification for our analysis, we use a micro-founded macroeconometric model similar to those studied by CEE and SW. Applying a Bayesian procedure to estimate this model with postwar U.S. data, we set the baseline values of the model parameters using the mean of the posterior distribution. We employ Lagrangian methods to determine the optimal policy under commitment in the baseline economy. Finally, we use second-order perturbation to solve the model and compute the level of welfare under the optimal policy as well as for alternative simple rules. ${ }^{7}$

We find that a simple interest rate rule that responds solely to nominal wage inflation and the lagged interest rate yields a welfare outcome that nearly matches that under the fully optimal policy. ${ }^{8}$ Because this rule only involves observable variables and does not require a measure of the output gap, the natural rate of interest, or forecasts of variables, the rule can be implemented without assuming that the policymaker knows the correct specification of the model or the true values of the model parameters.

The near-optimality of the simple wage stabilization rule is directly attributable to the overriding importance of nominal wage inertia in determining the welfare costs of aggregate fluctuations in the baseline economy. This inertia reflects the relatively long duration of nominal wage contracts as well as the nearly-uniform degree of indexation to lagged inflation. Furthermore, under our baseline specification of Calvo-style contracts with an exogenous probability of reoptimization, many wage contracts remain in effect much longer than the

\footnotetext{
${ }^{6}$ We do not explicitly consider the policy implications of uncertainty about the current state of the economy; for recent analysis of this issue, see Orphanides (2001), Croushore and Stark (2003), Svensson and Woodford (2003), Aoki (2003), Orphanides and Williams (2002), and Orphanides and Williams (2005).

${ }^{7}$ The optimal policy regime and optimized simple rules have previously been studied in micro-founded macroeconometric models by Onatski and N. Williams (2004), Levin and Lopez-Salido (2004), Laforte (2003), and Schmitt-Grohé and Uribe (2004).

${ }^{8}$ While we focus on simple interest rate rules in this paper, an alternative approach is to specify a simplified objective function for the central bank, as in the literature on flexible inflation targeting; see Svensson and Woodford (2004) and Giannoni and Woodford (2004). Although not reported here, our preliminary analysis suggests that stabilizing a wage inflation objective may also perform well in terms of welfare.
} 
one-year average duration. Thus, as emphasized by Erceg, Henderson, and Levin (2000), stabilizing aggregate wage inflation helps alleviate the degree of cross-sectional dispersion in real wages and thereby minimizes the associated inefficiencies in employment of differentiated labor services and in the allocation of leisure across households.

The simple wage stabilization rule is remarkably robust to parameter uncertainty and innovation uncertainty and to some modifications of the baseline model specification. For example, this rule yields near-optimal performance throughout the empirically relevant range of values of the model parameters, a finding consistent with our earlier work regarding the relatively minor importance of this type of uncertainty. ${ }^{9}$ The performance of the wage stabilization rule is also relatively insensitive to various assumptions regarding the nature and incidence of the innovations and to augmenting the model to incorporate monetary frictions.

Nevertheless, the policy implications can be quite sensitive to alternative specifications of the wage contracting mechanism. In particular, the welfare costs of nominal wage variability are much smaller when wages are determined by Taylor-style contracts with the same average duration as in our baseline specification of Calvo-style contracts. ${ }^{10}$ Thus, the simple wage stabilization rule is no longer nearly optimal, and better welfare outcomes are provided by other simple rules that respond to price inflation and real economic variables. Of course, as Hall (this volume) emphasizes, neither Calvo-style nor Taylor-style contracts provide the ideal microeconomic foundations for the determination of nominal wages and employment. Thus, our results should be interpreted as highlighting the extent to which additional research regarding the structure of labor markets is likely to have substantial benefits for the design of monetary stabilization policy.

The remainder of this paper is organized as follows. Section 2 provides an overview of the

\footnotetext{
${ }^{9}$ See Levin, Wieland, and J. Williams (1999), Levin, Wieland, and John C. Williams (2003), Levin and J. Williams (2003), and Onatski and N. Williams (2003).

${ }^{10}$ See Erceg and Levin (2005).
} 
baseline model specification. Section 3 briefly describes the estimation procedure and the posterior distribution of the model parameters. Section 4 characterizes the optimal policy in the baseline economy and compares the performance of alternative simple rules. Sections 5 and 6 analyze the implications of parameter uncertainty and innovation uncertainty, respectively. Section 7 considers several types of specification uncertainty. Section 8 concludes. The appendices contain some additional derivations and results.

\section{The Model}

As in CEE and SW, our baseline model incorporates a number of mechanisms that can induce intrinsic persistence in the propagation of shocks, including habit persistence in consumption, costs of adjustment for investment and capacity utilization, and staggered nominal wage and price contracts with partial indexation. The model also includes a number of exogenous disturbances (assumed to be mutually uncorrelated) that account for the stochastic variation in the observed data used in our estimation procedure.

\subsection{Household Preferences}

The economy has a continuum of infinitely lived households. The conditional welfare of a given household $h \in[0,1]$ at a given time $t$ is defined as the discounted sum of expected period utility:

$$
W_{t}(h)=E_{t} \sum_{j=0}^{\infty} \beta_{t+j}^{j} V_{t+j}(h),
$$

where the subjective discount factor is $\beta_{t}=\beta Z_{t}^{b}$ and we define $\beta_{t+j}^{j}=\prod_{s=0}^{j} \beta_{t+s}$. Thus, the steady-state subjective discount factor is given by the parameter $0<\beta<1$, while stochastic variation in the rate of time preference is induced by the exogenous disturbance $Z_{t}^{b}$; we assume that the logarithm of this disturbance follows an $\mathrm{AR}(1)$ process. 
The period utility function of a given household $h$ at time $t$ is specified as follows:

$$
V_{t}(h)=\frac{\left(C_{t}(h)-\theta C_{t-1}(h)\right)^{1-\sigma}}{1-\sigma}-\frac{Z_{t}^{L}\left(L_{t}(h)\right)^{1+\chi}}{1+\chi}+\mu_{0} \frac{Z_{t}^{m}\left(M_{t}(h)\right)^{1-\kappa}}{1-\kappa},
$$

where $C_{t}(h)$ denotes the household's total consumption, $L_{t}(h)$ denotes its labor hours, and $M_{t}(h)$ denotes its real cash balances. ${ }^{11}$ The preference parameters, $\sigma, \chi, \kappa$, and $\mu_{0}$, are strictly positive, while $\theta$ lies in the unit interval. The exogenous disturbance $Z_{t}^{L}$ induces stochastic variation in household preferences for leisure relative to consumption, and $Z_{t}^{m}$ is an exogenous shock to money demand; the logarithm of each shock is assumed to follow an $\operatorname{AR}(1)$ process.

Habit persistence in consumption is an important but somewhat controversial feature of this specification. In particular, for positive values of $\theta$, the household's lagged consumption effectively serves as a reference value in determining the period utility generated by current consumption. ${ }^{12}$ Recent empirical analysis of aggregate data has obtained substantial evidence of habit persistence; for example, CEE emphasize its role explaining the hump-shaped behavior of aggregate consumption in response to a monetary policy shock. Nevertheless, it should be noted that micro-level studies have occasionally obtained results that directly conflict with the macro evidence. ${ }^{13}$

Of course, the curvature parameters of the utility function also remain quite controversial. Some studies have argue that $\sigma$ is around unity, while others find much larger values. ${ }^{14}$ Furthermore, microeconometric studies have typically obtained estimates of $\chi$ that are significantly greater than unity, whereas some macroeconomists have argued that the aggregate

\footnotetext{
${ }^{11}$ We interpret $M_{t}$ as broad money and assume that households invest the remainder of their assets $A_{t}-M_{t}$ with a financial intermediary earning the nominal interest rate $R_{t}$.

${ }^{12}$ Some authors have considered an alternative specification, referred to as "external habit persistence," in which the lagged value of aggregate consumption serves as the reference value for each individual household. In the absence of offsetting taxes, this formulation poses an externality that distorts the steady state; thus, given our emphasis on the stabilization role of monetary policy, in this paper we focus exclusively on the "internal habit" specification given in the text.

${ }^{13}$ For example, see the contrast between the conclusions of Fuhrer (2000) and Dynan (2000).

${ }^{14}$ See Guvenen (2005) for a recent survey of the literature and an attempt to reconcile the differences in published estimates.
} 
data are consistent with a near-zero value of $\chi$, corresponding to a very high intertemporal elasticity of leisure for the representative household. ${ }^{15}$

Finally, while this specification allows real money balances to directly influence household utility, most of our analysis will focus on the "cashless economy" emphasized by Woodford (2003) and others; this economy corresponds to the limiting case in which $\mu_{0}$ becomes arbitrarily small. Later in the paper, however, we will revisit this issue and examine the policy implications of incorporating a non-trivial role for money into the model.

\subsection{Production and Prices}

The final composite good-used for both consumption and investment-is obtained by bundling together a continuum of differentiated intermediate goods using a Dixit-Stiglitz aggregator function. As in SW, we allow the elasticity of substitution between different goods to exhibit exogenous temporal variation; that is, $\lambda_{t}^{p}=Z_{t}^{p} \lambda^{p}$. The parameter $\lambda^{p}>0$ determines the steady-state markup rate, while the exogenous disturbance $Z_{t}^{p}$ (assumed to have an i.i.d. log-normal distribution) shifts the desired markup at each point in time. A given firm, indexed by $i \in[0,1]$, as the sole producer of intermediate good $i$, faces a downward-sloping demand curve, and its elasticity of demand $-\left(1+\lambda_{t}^{p}\right) / \lambda_{t}^{p}$ is invariant to the firm's level of production. ${ }^{16}$

Interestingly, the steady-state markup parameter $\lambda^{p}$ does not influence the first-order dynamics of the model economy and hence cannot be estimated using the methods employed in this paper. Nevertheless, this parameter does affect the second-order properties of the model, including the welfare performance of monetary policy rules. In light of the available

\footnotetext{
${ }^{15}$ See Huang and Liu (2004) for a summary of recent evidence regarding the intertemporal elasticity of labor supply at the intensive and extensive margins.

${ }^{16}$ Kimball (1995) proposed a more general form of aggregator function that allows for quasi-kinked demand curves, and several recent empirical studies have analyzed its first-order implications; cf. Eichenbaum and Fisher (2004), Altig, Christiano, Eichenbaum, and Linde (2004), and Coenen and Levin (2004). However, higher-order approximations of the Kimball specification have not yet been considered and remain well beyond the scope of the present analysis.
} 
evidence from disaggregated data, we set $\lambda^{p}=0.20$ in the baseline version of the model, and then consider alternative values from 0.1 to $0.5 .^{17}$

Every intermediate-goods producer has an identical production function that determines the gross output of good $i$ as a Cobb-Douglas function of the firm's employment of labor services $N_{t}(i)$, its rental of capital services $\tilde{K}_{t}(i)$, and the exogenous economy-wide productivity factor $A_{t}$ :

$$
Y_{t}(i)=A_{t} \tilde{K}_{t}(i)^{\alpha} N_{t}(i)^{1-\alpha}-\Phi
$$

where the parameter $\alpha$ represents the share of capital in gross output, and we assume that the logarithm of the productivity factor follows an AR(1) process. As in CEE and SW, every firm hires its capital and labor services on competitive economy-wide markets and hence has the same marginal cost of production.

The firm's net output $Y_{t}(i)$ reflects the presence of the fixed overhead cost $\Phi$. This fixed cost induces locally increasing returns to scale for each individual firm, and generates procyclical total factor productivity at the aggregate level. Thus, inferences about the value of $\Phi$ can be made using both micro-level and macro-level data.

In the baseline version of the model, we assume that prices are determined by Calvostyle nominal contracts with partial indexation. ${ }^{18}$ In particular, every firm faces a constant probability $1-\xi_{p}$ of reoptimizing its price contract in any given period, where $\xi_{p} \in[0,1]$; thus, price contracts have an average duration $1 /\left(1-\xi_{p}\right)$. Whenever the contract is not reoptimized, the firm's price is automatically adjusted by the lagged rate of inflation raised to the power $\gamma_{p} \in[0,1]$.

This specification of price-setting behavior provides formal underpinnings for the hybrid New Keynesian Phillips curve. ${ }^{19}$ In particular, the indexation parameter $\gamma_{p}$ determines the

\footnotetext{
${ }^{17}$ For empirical analysis of demand elasticities and markups, see Shapiro (1987), Basu (1996), and Basu and Fernald (1997).

${ }^{18}$ See Yun (1996) and Woodford (2003) for analysis of the microeconomic underpinnings of the contract structure introduced by Calvo (1983).

${ }^{19}$ See Clarida, Gali, and Gertler (1999) and Woodford (2003).
} 
relative weight on the "backward-looking" vs. "forward-looking" terms in the hybrid Phillips curve. While the magnitude of these weights is subject to ongoing controversy, recent analysis of aggregate data seems to be largely consistent with the available microeconomic evidence indicating that indexation is not a typical characteristic of price adjustment. ${ }^{20}$

Under the assumption that all firms have the same marginal cost, the responsiveness of inflation to current marginal cost is determined solely by the parameter $\xi_{p}$. Typically, as in SW, the estimated value of $\xi_{p}$ tends to imply a relatively long average duration of price contracts that is inconsistent with recent microeconomic evidence. ${ }^{21}$ Several recent studies have shown that incorporating additional real rigidities-such as quasi-kinked demand and firm-specific capital-yields more plausible estimates of the degree of nominal rigidity. ${ }^{22} \mathrm{Nev-}$ ertheless, analyzing the second-order implications of these mechanisms poses some technical challenges that remain to be addressed in the literature.

\subsection{Investment and Capacity Utilization}

Households own the entire stock of physical capital $K_{t}$. Capital accumulation is subject to adjustment costs that are assumed to be proportional to the squared growth rate of investment, rather than the more traditional formulation involving the squared level of investment. As emphasized by CEE, this specification of adjustment costs can generate a hump-shaped response of aggregate investment to a monetary policy shock, consistent with the implications of an identified vector autoregression. While the formal microeconomic foundations of this mechanism were initially opaque, Basu and Kimball (2003) have subsequently shown that

\footnotetext{
${ }^{20}$ For aggregate evidence on the degree of intrinsic inflation persistence, see Gali, Gertler, and Lopez-Salido (2001) and Levin and Piger (2004). For a recent discussion of the microeconomic evidence, see Angeloni, Aucremanne, Ehrmann, Gali, Levin, and Smets (2004).

${ }^{21}$ See Bils and Klenow (2004), Klenow and Kryvtsov (2004), and Dhyne, Alvarez, Bihan, Veronese, Dias, Hoffmann, Jonker, Lnnemann, Rumler, and Vilmunen (2005).

${ }^{22}$ Sveen and Weinke (2004) and Woodford (2005) consider the analytical foundations of firm-specific capital, while empirical studies include Sbordone (2002), Gali, Gertler, and Lopez-Salido (2001), Eichenbaum and Fisher (2004), Altig, Christiano, Eichenbaum, and Linde (2004), and Coenen and Levin (2004).
} 
very similar implications can be obtained in a framework with planning delays in investment.

Thus, the capital stock owned by a given household $h \in[0,1]$ evolves as follows:

$$
K_{t}(h)=(1-\delta) K_{t-1}(h)+\left[1-\zeta^{-1} \frac{1}{2}\left(Z_{t}^{I} \frac{I_{t}(h)}{I_{t-1}(h)}-1\right)^{2}\right] I_{t}(h),
$$

where $K_{t}(h)$ denotes the household's beginning-of-period capital stock and $I_{t}(h)$ denotes the gross investment during period $t$. The depreciation rate is given by $\delta$, and the parameter $\zeta$ gauges the magnitude of investment adjustment costs. ${ }^{23}$ Finally, the exogenous disturbance $Z_{t}^{I}$ acts as an economy-wide shock to investment demand; its logarithm follows an AR(1) process.

In each period, the aggregate flow of capital services $\tilde{K}_{t}$ to the intermediate goods sector is defined as the capacity utilization rate $U_{t}$ multiplied by the predetermined level of the physical capital stock, $K_{t-1}$. The capacity utilization rate can vary from its steady-state value of unity, but such variations are associated with a real resource cost. In particular, we specify the resource cost $\Psi_{t}(h)$ incurred by a given household $h$ as a CES function of its capacity utilization $U_{t}(h)$ :

$$
\Psi_{t}(h)=\mu \frac{U_{t}(h)^{1+\psi^{-1}}-1}{1+\psi^{-1}}
$$

where $\psi \geq 0$ and $\mu>0 .^{24}$

As emphasized by CEE, variable capacity utilization can effectively enhance the shortterm flexibility of the economy in response to aggregate shocks. Nevertheless, the magnitude of the utilization cost parameter $\psi$ is currently subject to a great deal of uncertainty, due both to the scarcity of microeconomic evidence and to conflicting results from recent macroeconometric analysis. For example, CEE find that variations in capacity utilization play an

\footnotetext{
${ }^{23}$ This adjustment cost specification incorporates the basic properties assumed by CEE and SW, who were only concerned with characterizing the steady state and log-linear properties of the model. By using an explicit definition of the adjustment cost function, we are able to analyze the second-order approximation of the model economy.

${ }^{24}$ As with investment adjustment costs, this explicit specification incorporates the basic properties assumed by CEE and SW, while enabling us to analyze the second-order approximation of the model economy.
} 
important role in explaining the sluggish response of inflation to a monetary policy shock, whereas the results of Altig, Christiano, Eichenbaum, and Linde (2004) suggest that the aggregate effects of a technology shock are only consistent with relatively limited variations in capacity utilization.

Finally, following SW, we include an "external finance premium" shock $Z_{t}^{q}$ (assumed to have an i.i.d. log-normal distribution) which acts as a wedge between the risk-free real interest rate and the required expected rate of return on physical capital. Recent analysis of firm-level data has obtained precise estimates of the magnitude and cyclical behavior of the external finance premium; cf. Levin, Natalucci, and Zakrajsek (2004). However, further theoretical and empirical research is clearly needed to elucidate the underpinnings and implications of this mechanism.

\subsection{Employment and Wages}

Households provide a continuum of differentiated labor services, which are bundled together using a Dixit-Stiglitz aggregator function and then rented to the intermediate sector. As in SW, we allow the elasticity of substitution between different types of labor services to ex-

hibit exogenous temporal variation; that is, $\lambda_{t}^{w}=Z_{t}^{w} \lambda^{w}$. The parameter $\lambda^{w}>0$ determines the steady-state markup of real wages over the marginal rate of substitution between consumption and leisure. The exogenous disturbance $Z_{t}^{w}$ (assumed to have an i.i.d. log-normal distribution) shifts the desired wage markup at each point in time. Given this specification, a given household $h \in[0,1]$, as the sole provider of the labor service of type $h$, faces a downward-sloping labor demand curve with elasticity $-\left(1+\lambda_{t}^{w}\right) / \lambda_{t}^{w}$.

In the baseline version of the model, we assume that wages are determined by Calvo-style nominal contracts with partial indexation. In particular, each household faces a constant probability $1-\xi_{w}$ of reoptimizing its wage contract in any given period, where $\xi_{w} \in[0,1]$. Whenever the contract is not reoptimized, the household's wage is automatically adjusted 
by the lagged rate of price inflation raised to the power $\gamma_{w} \in[0,1]$.

The steady-state markup parameter $\lambda^{w}$ and the contract wage parameter $\xi_{w}$ cannot be independently identified from the log-linear dynamics of the model. Given the scarcity of disaggregated evidence on these two parameters, we proceed by calibrating $\lambda^{w}=0.20$ (the same baseline value as for $\lambda^{p}$ ) and estimating the value of $\xi_{w} \cdot{ }^{25}$ We will then gauge the policy and welfare implications of alternative combinations of these two parameters that yield the same first-order behavior of the model.

Because the wage-setting mechanism has crucial implications for the design of optimal monetary policy, we will also consider two modifications to the baseline specification, namely, indexation of wages to lagged wage inflation instead of lagged price inflation and the use of fixed-duration "Taylor-style" wage contracts instead of Calvo-style contracts. As we will see, these alternative specifications yield significantly different implications for monetary policy and welfare.

\subsection{Fiscal and Monetary Policy}

We assume that government spending is exogenously determined and exhibits persistent variations; in particular, its logarithm follows an $\mathrm{AR}(1)$ process. As is evident from the previous discussion, government spending has no direct effects on either utility (through purchases of public goods) or production (perhaps via a stock of public capital); consideration of these channels, as well as automatic fiscal stabilizers, is deferred to future research.

Furthermore, we assume that the government offsets the steady-state effects of monopolistic distortions by enacting the appropriate magnitude of production and employment subsidies, which are financed via a constant level of lump-sum taxes. Thus, the deterministic steady state is Pareto-optimal in the baseline model with a zero inflation rate. Under

\footnotetext{
${ }^{25}$ Taylor (1999b) provides an overview of the evidence on nominal wage inertia. For analysis of the elasticity of demand for differentiated labor services, see Griffin (1996a), Griffin (1996b).
} 
these assumptions, we can focus our analysis on the stabilization task of monetary policy, abstracting from the complications that would arise if the central bank also played a role in trying to offset the effects of steady-state distortions. ${ }^{26}$

In estimating the model, we use a fairly simple monetary policy rule in which the shortterm nominal interest rate responds to the lagged interest rate as well as to deviations of aggregate price inflation from target and of actual output from the level that would prevail in the absence of nominal inertia. This specification includes two additional exogenous shocks, namely, persistent $\mathrm{AR}(1)$ shifts in the inflation objective and transitory white-noise shocks to the current policy rate. In our normative analysis, of course, we consider the full Ramsey policy as well as alternative specifications of simple policy rules, and we assume that monetary policy does not exhibit any exogenous stochastic variation.

\section{Model Estimation}

We employ Bayesian methods to estimate the log-linearized version of the model, using quarterly U.S. data over the period 1955:1 through 2001:4. ${ }^{27}$ In particular, we treat seven aggregate variables as directly observed: real consumption, real investment, real GDP, real wages, total hours, GDP price inflation, and the federal funds rate. ${ }^{28}$ Because the rest of the model variables (such as the capital stock) are treated as unobserved, we use the Kalman filter in computing the likelihood function of the model.

As widely recognized in earlier work, certain structural parameters are not well-identified from the cyclical dynamics of the data. Therefore, we use long-term historical averages to

\footnotetext{
${ }^{26}$ For analysis of optimal policy in economies with steady-state distortions, see Benigno and Woodford (2004) and Schmitt-Grohe and Uribe (this volume).

${ }^{27} \mathrm{~A}$ detailed description of the log-linearized model is provided in Appendix B.

${ }^{28}$ We use the same dataset as in Altig, Christiano, Eichenbaum, and Linde (2004), obtained from Martin Eichenbaum's web page. The real wage is constructed as non-farm wage rate adjusted by the GDP price deflator, while total hours are measured for the non-farm business sector. The inflation rate and interest rate are demeaned and converted to quarterly rates; the other five variables are measured in logarithmic deviations from linear trends, in percentage points.
} 
specify the values of these parameters: the capital share parameter $\alpha=0.36$; the discount factor $\beta=0.99$ (corresponding to a steady-state real interest rate of about 4 percent); and the depreciation parameter $\delta=0.025$ (corresponding to an annual rate of about 10 percent). Similarly, we calibrate the output shares of consumption, investment, and government spending at $c_{y}=\bar{C} / \bar{Y}=0.56, i_{y}=0.24$, and $g_{y}=0.20$, respectively. ${ }^{29}$ Finally, we set the wage and price markup parameters $\lambda^{w}=\lambda^{p}=0.2$; in the following section, we will consider the implications of alternative values for these two parameters.

We formulate independent prior densities for each of the other 31 parameters of the model, namely, ten parameters related to preferences and technology, five coefficients of the empirical interest rate reaction function, and sixteen parameters of the data-generating processes for the disturbances. Overall, our prior is consistent with the previous literature and is relatively uninformative for most of the parameters; details are given in the appendix. ${ }^{30}$ Given these priors, we characterize the posterior distribution using a Metropolis-Hastings Markov chain Monte Carlo (MCMC) algorithm. Our estimation methodology is broadly similar to that of Lubik and Schorfheide (2005); further details are provided in the appendix. ${ }^{31}$

In the remainder of this section, we focus on characterizing the posterior distribution of the key structural parameters. Table 1 reports the posterior means and the $5 \%$ and $95 \%$ bounds for each of these parameters, while corresponding results for the parameters of the shock processes may be found in the appendix.

As depicted in Figure 1, the macroeconomic data are quite informative regarding the parameters related to price and wage determination. In light of recent micro-based evidence

\footnotetext{
${ }^{29}$ The mean ratio of net exports to GDP was zero to two decimal points over our sample.

${ }^{30}$ In specifying these priors, we have drawn heavily on Smets and Wouters (2003a), (Smets and Wouters 2003b), Christiano, Eichenbaum, and Evans (2005), Altig, Christiano, Eichenbaum, and Linde (2004), and Onatski and N. Williams (2004).

${ }^{31}$ Since the work of Schorfheide (2000) and especially after the original Smets and Wouters (2003a) paper there have been a number of papers using Bayesian methods for models similar to ours; examples include Del Negro and Schorfheide (2004), Rabanal and Rubio-Ramirez (2003), Laforte (2003), Onatski and N. Williams (2004), and del Negro, Schorfheide, Smets, and Wouters (2004).
} 

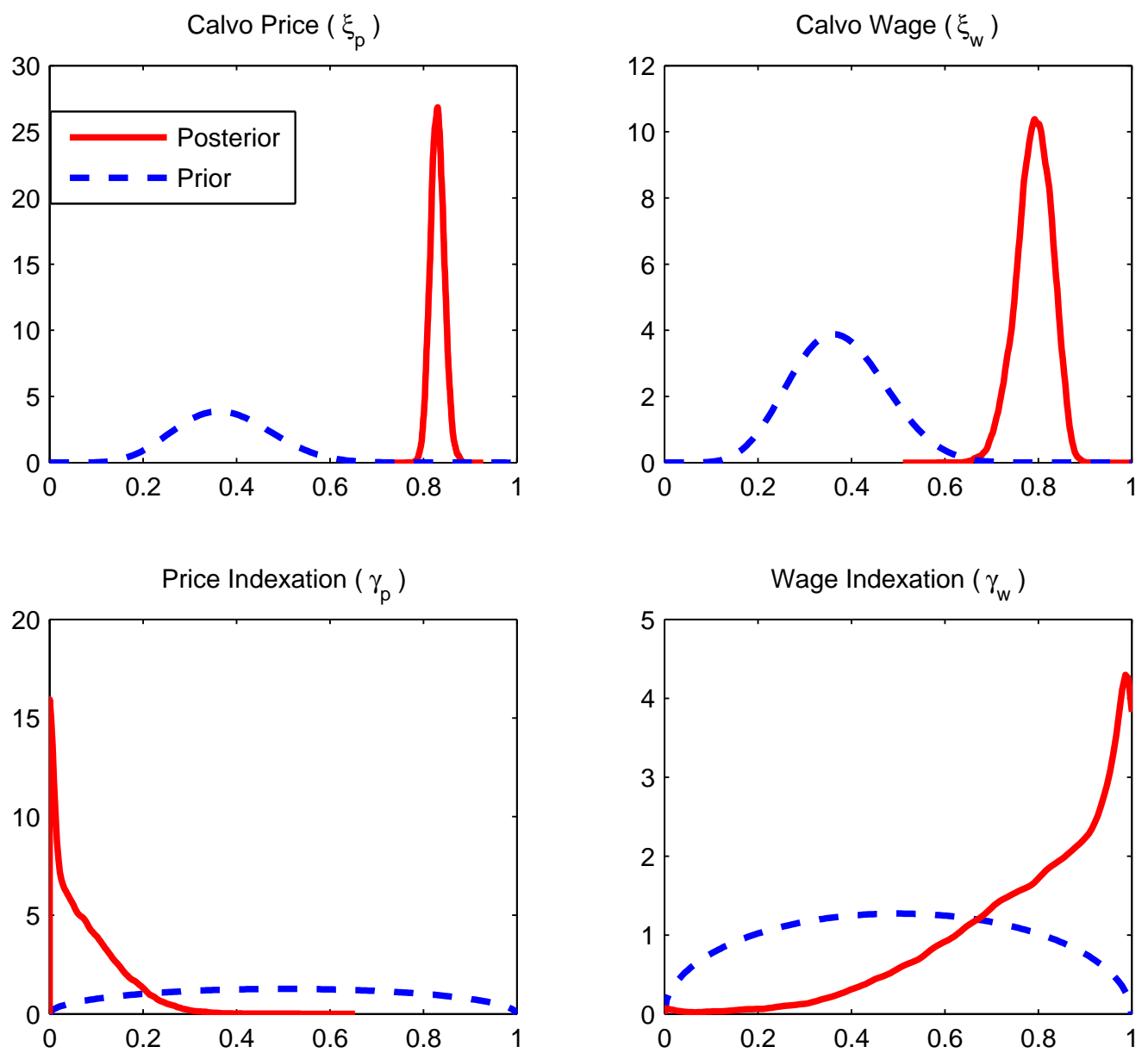

Figure 1: Estimated posterior distributions (red solid lines) and prior distributions (blue dashed) for the price and wage parameters. 
Table 1: Estimation Results

\begin{tabular}{llcclc}
\hline \hline & & $\begin{array}{c}\text { Posterior } \\
\text { Parameter }\end{array}$ & \multicolumn{2}{c}{$\begin{array}{c}90 \% \\
\text { Mean }\end{array}$} & \multicolumn{2}{c}{ Intervability } \\
\hline \hline$\xi_{p}$ & Calvo prices & 0.83 & 0.81 & - & 0.86 \\
$\xi_{w}$ & Calvo wages & 0.79 & $0.72-$ & 0.85 \\
$\gamma_{p}$ & Price indexation & 0.08 & $0.00-$ & 0.21 \\
$\gamma_{w}$ & Wage indexation & 0.79 & $0.43-$ & 1.00 \\
$\zeta$ & Investment adjustment & 0.56 & $0.27-$ & 0.86 \\
$\sigma$ & Consumption utility & 2.19 & $1.68-$ & 2.74 \\
$\theta$ & Consumption habit & 0.29 & $0.20-$ & 0.38 \\
$\chi$ & Labor utility & 1.49 & $0.95-$ & 2.12 \\
$\phi$ & Fixed cost & 1.09 & $1.06-$ & 1.11 \\
$\psi$ & Capital utilization & 0.21 & $0.12-$ & 0.31 \\
\hline \hline
\end{tabular}

obtained by Bils and Klenow (2004) and Golosov and Lucas (2003), we specify a prior mean of 0.38 for the Calvo price-setting parameter $\xi_{p}$, corresponding to an average contract duration of about 1.5 quarters; we employed the same prior mean for the Calvo wage parameter $\xi_{w}$. In contrast, the posterior mean estimates for these two parameters imply an average contract duration of about five quarters, similar to the findings of CEE and SW. ${ }^{32}$ Furthermore, the posterior probability intervals of these estimates are relatively narrow, suggesting a fairly clear disconnect between the micro and macro evidence.

We impose relatively uninformative priors on the degree of price and wage indexation. The estimate of the degree of price indexation is near zero and relatively precisely estimated; in contrast, the degree of wage indexation is found to be substantial, but very imprecisely estimated. The lack of price indexation differs from SW but is consistent with the findings of Ireland (2001) and Edge, Laubach, and J. Williams (2003).

The macroeconomic data are somewhat less informative regarding other structural parameters. Figure 2 repeats the previous figure for the structural parameters not related to price and wage determination. Overall, the resulting estimates are consistent with estimates

\footnotetext{
${ }^{32}$ For comparison, Taylor (1993b), using a staggered wage model, estimates an average wage contract duration of about $3-1 / 2$ quarters.
} 

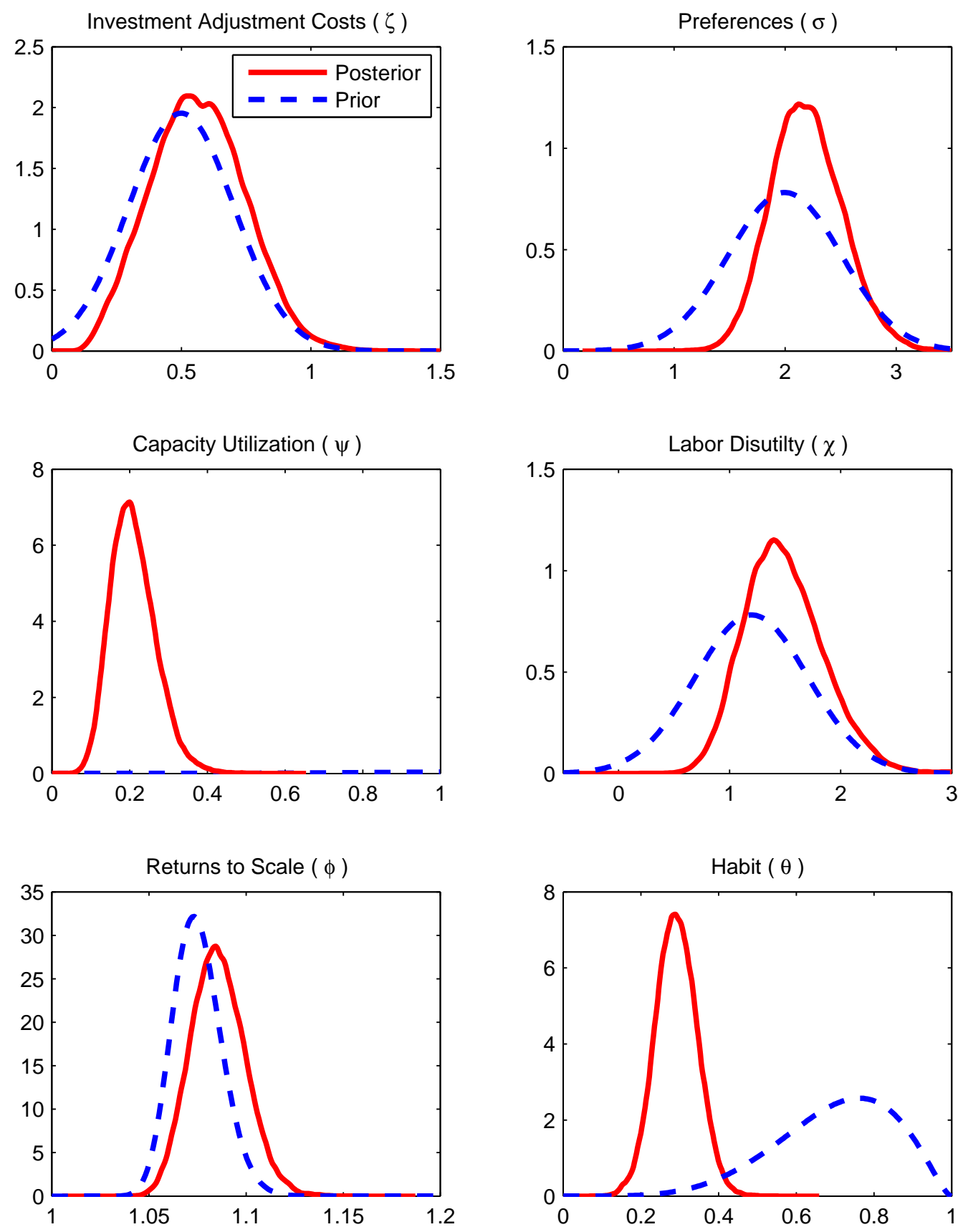

Figure 2: Estimated posterior distributions (red solid lines) and prior distributions (blue dashed) for structural parameters. 
from the literature. Except for the parameters determining capacity utilization costs and habit persistence, the posteriors do not differ greatly from the respective priors. The finding of a relatively tight posterior distribution for the capacity utilization cost parameter occurs despite the imposition of a relatively loose prior and contrasts with the wide dispersion of estimates of this parameter in the literature.

One structural parameter that deserves further discussion is the returns to scale in production, $\phi$. We chose a relatively tight prior centered on 1.08 for this parameter, based on the estimates of Basu (1996) and Basu and Fernald (1997), who find fixed costs of between 3 and 10 percent. Our resulting mean estimate is 1.09. By comparison, when we imposed an uninformative prior, the mode estimate exceeded 2 , a result consistent with the findings of SW, but contrary to the micro evidence. Despite this difference in point estimates, in fact the data were not terribly informative about this parameter, as seen in the figure. Interestingly, imposing our prior on $\phi$ resulted in a small estimate of investment adjustment costs. Our estimate of investment adjustment costs are noticeably lower than SW, but more in line with those reported by ACEL.

For the monetary policy reaction function, we obtain the following estimation results:

$$
r_{t}=\underset{(0.03)}{0.84} r_{t-1}+0.16\left[\begin{array}{l}
2.7 \\
(0.3)
\end{array}\left(\pi_{t-1}-\pi_{t-1}^{*}\right)+\underset{(0.07)}{0.10} y_{t-1}\right]+\underset{(0.06)}{0.26} \Delta \pi_{t}+\underset{(0.07)}{0.51} \Delta y_{t}+\eta_{t}^{r}
$$

where the estimated standard error of each coefficient is enclosed in parentheses. This reaction function exhibits a high degree of inertia, a strong long-run response to inflation, modest sensitivity to the level of the output gap, and a sizeable response to changes in the output gap.

As for the monetary policy shocks, we find that the inflation target $\pi_{t}^{*}$ has significant variation and exhibits very high persistence approaching that of a random walk, while the transitory disturbance $\eta_{t}^{r}$ has negligible variance. It should be noted that our modeling framework does not provide any rationale or potential benefits from a time-varying inflation 
target or from idiosyncratic disturbances to the policy rule. Thus, given our focus on policies that maximize social welfare, henceforth we eliminate these two shocks by setting their variances to zero.

\section{Optimal Monetary Policy}

In this section, we characterize the monetary policy implications of the baseline model at the posterior mean values of the estimated parameters, abstracting from uncertainty about the true structure of the economy. We start by considering the optimal policy under commitment that maximizes conditional expected welfare, and then compare the performance of simple rules in which the short-term interest rate is adjusted in response to one or more observable variables.

\subsection{The Optimal Policy Problem}

The optimal policy under commitment can be computed by formulating an infinite-horizon Lagrangian problem, in which the central bank maximizes conditional expected social welfare subject to the full set of non-linear constraints implied by the private sector's behavioral equations and the market-clearing conditions of the model economy. ${ }^{33}$ The first-order conditions of this problem are obtained by differentiating the Lagrangian with respect to each of the endogenous variables (including the policy instrument) and setting these derivatives to zero. Of course, performing these derivations by hand would be extremely tedious; thus, we utilize the symbolic Matlab procedures developed by Levin and Lopez-Salido (2004). ${ }^{34}$

We then proceed to analyze the behavior of the economy under optimal policy by combining the central bank's first-order conditions together with the private sector's behavioral equations and the market-clearing conditions. Thus, the size of the model is much larger

\footnotetext{
${ }^{33}$ See Kydland and Prescott (1980), King and Wolman (1999), and Khan, King, and Wolman (2003).

${ }^{34}$ These procedures are available on the Dynare website or on request from the authors.
} 
under the optimal policy, because these first-order conditions take the place of a single interest rate reaction function, while the set of Lagrange multipliers is added to the list of model variables. Nevertheless, it should be emphasized that no new parameters have been added to the model, because the central bank's first-order conditions involve the same structural parameters as in the behavioral equations and market-clearing conditions.

Because this set of non-linear equations involves rational expectations, numerical methods are required to characterize the equilibrium properties of the stochastic economy. ${ }^{35}$ Furthermore, while the first-order dynamics can be investigated by log-linearizing the model, higher-order methods are needed to evaluate conditional expected welfare. ${ }^{36}$ Therefore, we employ the DYNARE software package of Juillard (2001) to compute the second-order approximation of the model economy. ${ }^{37}$

Finally, as in Levin and Lopez-Salido (2004), our analysis is focused on evaluating the welfare cost of business cycles; that is, for each monetary policy regime, we measure how conditional expected welfare changes in response to the stochastic variation of the model economy. ${ }^{38}$ Throughout the paper, welfare costs are expressed in terms of the equivalent percent decline in steady-state consumption.

\subsection{Characteristics of Optimal Policy}

The deterministic steady state of the baseline economy is characterized by a zero inflation rate. In particular, as noted above, we assume that fiscal subsidies offset the steady-state monopolistic distortions to production and employment, while money is essentially absent from the baseline specification. Thus, in the absence of stochastic shocks, the central bank's

\footnotetext{
${ }^{35}$ Judd (1998) provides a general introduction and comparison of methods for solving non-linear rational expectations models.

${ }^{36}$ See Kim and Kim (2003), Kim, Kim, Schaumburg, and Sims (2003), and Woodford (2003).

${ }^{37}$ Because perturbation methods provide a local approximation around the steady state, our analysis does not consider the implications of the zero lower bound on nominal interest rates.

${ }^{38}$ For this purpose, it is essential to utilize conditional mean-preserving spreads for the exogenous disturbances; see Levin and Lopez-Salido (2004) for further discussion.
} 
sole task is to choose the constant inflation rate that minimizes the degree of cross-sectional dispersion in prices and wages; indeed, by maintaining a zero inflation rate, monetary policy succeeds in implementing the Pareto-optimal equilibrium in steady state.

The first-order implications of the optimal policy are shown in Figure 3, which depicts the response of selected macro variables to an exogenous rise in the productivity factor. ${ }^{39}$ The optimal policy (solid line) yields a path of short-term real interest rates that closely resembles that of the "real business cycle" (RBC) economy with flexible wages and prices (dot-dashed line); in contrast, real interest rates are nearly constant under the empirical reaction function (dashed line). In the $\mathrm{RBC}$ economy, real wages initially rise about $3 / 4$ percent; with a constant price level, this adjustment occurs solely through a surge in nominal wage inflation. In contrast, the optimal policy for the baseline economy is mainly oriented towards minimizing cross-sectional dispersion in wage rates, and hence permits a noticeable decline in prices while nominal wage inflation remains close to zero.

Under the optimal policy (as in the RBC economy), the positive shock to productivity induces a substantial decline in aggregate labor hours that is gradually reversed over the subsequent year. Under the empirical reaction function, labor hours only decline for a single quarter and then rise above baseline. These findings relate to the debate regarding the empirical evidence of the response of hours to productivity shocks and the sensitivity of these results to monetary policy.

We now compare the welfare implications of these policies for the baseline economy with stochastic variation in all of the exogenous disturbances except the monetary policy shocks. For each policy, Table 2 reports the welfare cost of business cycles in terms of the equivalent percentage point change in steady-state consumption; this table also indicates welfare outcomes for two simple rules that are discussed further below.

Under the empirical reaction function, the welfare cost of business cycles in the baseline

\footnotetext{
${ }^{39}$ Impulse responses for other structural shocks are reported in the Appendix.
} 

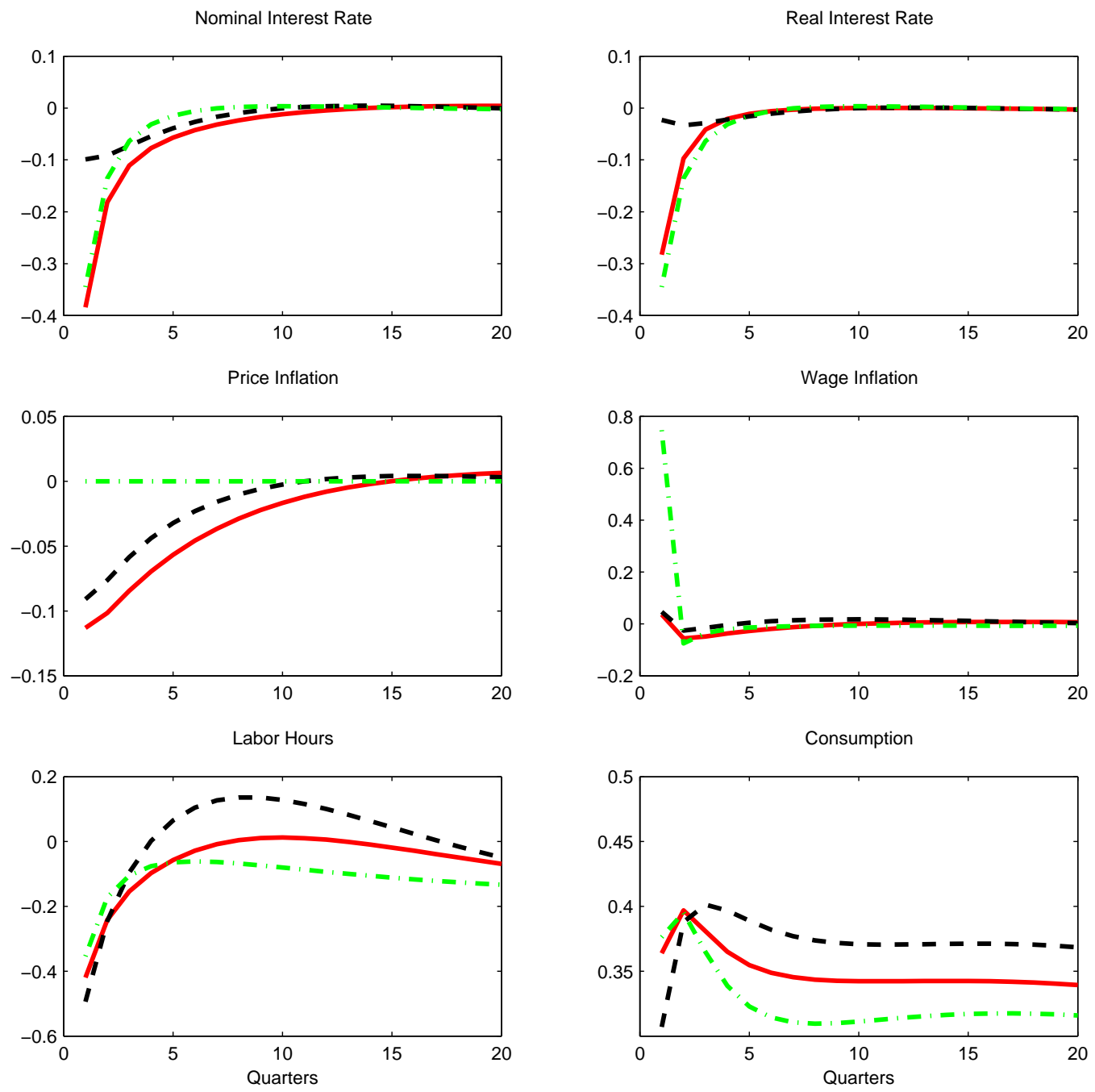

Figure 3: Impulse responses for one standard deviation positive shock to productivity; optimal policy (solid lines), empirical reaction function (dashed), RBC economy (dash-dotted lines). 
Table 2: The Welfare Cost of Business Cycles

\begin{tabular}{ll} 
Empirical reaction function & -2.57 \\
Optimized price inflation rule & -2.60 \\
Optimized wage inflation rule & -2.13 \\
Optimal policy & -2.01 \\
\hline \hline
\end{tabular}

model is equivalent to a permanent 2.6 percent reduction in household consumption. The optimal policy is associated with a markedly lower cost of business cycles, equivalent to about 2 percent of steady-state consumption. It should be noted that these welfare costs are an order of magnitude larger than in the results emphasized by Lucas (2003), mainly because staggered contracts induce substantial cross-sectional dispersion in relative prices and wages. ${ }^{40}$

To gauge these welfare results more concretely, we note that U.S. personal consumption expenditures were about $\$ 28,000$ per person in 2004 ; thus, switching from the empirical reaction function to the optimal policy would permanently raise welfare by about $\$ 160$ per person, while eliminating all stochastic variation in the economy would generate a permanent welfare gain exceeding $\$ 700$ per person. As we will see below, however, the magnitude of the welfare costs can be quite sensitive to the parameter values of the model as well as to the specification of the innovations and the determination of wages and prices.

\subsection{Simple Policy Rules}

We now consider the performance of simple policy rules with coefficients chosen to maximize welfare in the baseline model. ${ }^{41}$ In particular, we examine rules with the following form:

$$
r_{t}=r_{i} r_{t-1}+r_{\pi} \pi_{t}+r_{\omega} \omega_{t}
$$

\footnotetext{
${ }^{40}$ For related analysis and results, see Cho, Cooley, and Phaneuf (1997), Canzoneri, Cumby, and Diba (2004), and Paustian (2004).

${ }^{41}$ For analysis and discussion of the rationale for simple rules, see Taylor (1993a) and Williams (2003).
} 
where the nominal interest rate $r_{t}$ responds to the price inflation rate $\pi_{t}$ and the nominal wage inflation rate $\omega_{t}$ as well as to the lagged nominal interest rate. This type of rule is operational in the sense of McCallum (1999), in the sense that the policy instrument is determined only by observable variables, and not by model-specific constructed data such as the natural rates of interest and output, and forecasts of variables (which require knowledge of the economy). ${ }^{42}$ Furthermore, it is equivalent to targeting a deterministic path for the level of wages or prices; such policies have been shown to perform very well in the presence of the zero lower bound on nominal interest rates. ${ }^{43}$

Given the role of wage dispersion in determining the welfare cost of business cycles, it is useful to consider policy rules that respond directly to nominal wage inflation, as suggested by Erceg, Henderson, and Levin (2000). ${ }^{44}$ Therefore, we consider a hybrid rule that responds differentially to both price and wage inflation, as well as rules that respond to price inflation alone. Optimizing the coefficients of the hybrid rule to maximize welfare in the baseline model, we find that $r_{\omega}=3.2$ while $r_{\pi}=0$. Thus, given that the optimized rule does not actually respond to price inflation, we simply refer to this rule as the benchmark wage inflation rule. We then compare its performance to an alternative rule that does not respond to wages-henceforth referred to as the benchmark price inflation rule-for which welfare optimization yields $r_{\pi}=2.1$.

As indicated in Table 2, the benchmark wage inflation rule yields a welfare outcome nearly identical to the optimal policy; indeed, following this simple wage inflation rule rather than the optimal policy would incur a welfare cost equivalent to less than $\$ 35$ per person per year. In contrast, the benchmark price inflation rule yields a welfare loss that is roughly the same as under the empirical reaction function.

\footnotetext{
${ }^{42}$ McCallum (1999) also highlights the role of information lags; thus, while our specification utilizes contemporaneous data, it will be useful to consider this issue further in subsequent research.

${ }^{43}$ See Reifschneider and Williams (2000), Eggertsson and Woodford (2003), and others.

${ }^{44}$ See also Erceg and Levin (2005) and Mankiw and Reiss (2002).
} 

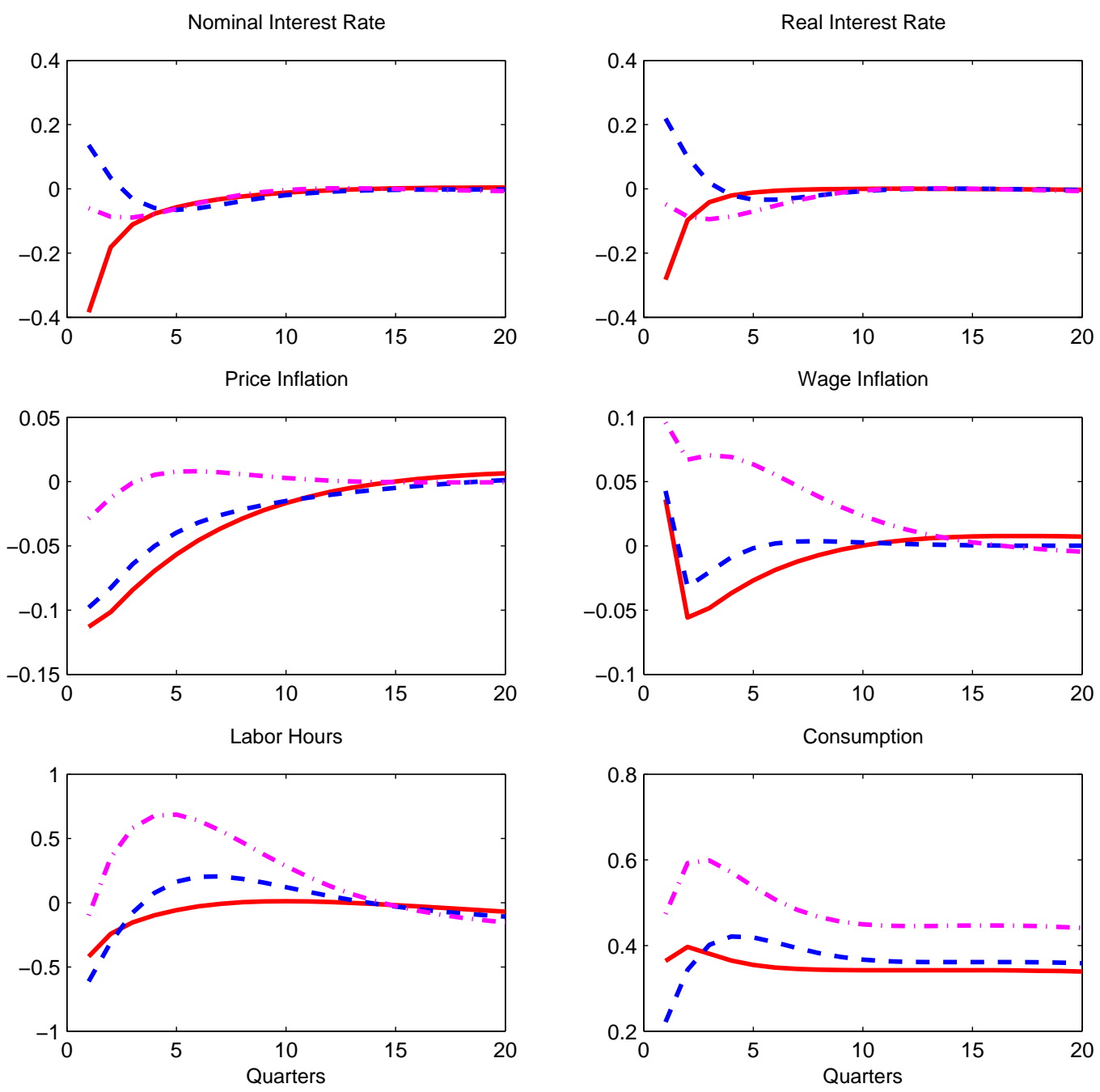

Figure 4: Impulse responses for one standard deviation positive shock to productivity; optimal policy (solid lines), optimized wage inflation rule (dashed lines), and the optimized price inflation rule (dash-dot lines). 
The impulse responses to the technology shock under the benchmark wage inflation rule mimics closely those of the optimal policy, as seen in Figure 4. One difference is that the benchmark wage inflation rule initially tightens monetary policy, causing a slightly excessive fall in labor hours and consumption at the onset of the shock. After a few quarters, however, the benchmark wage inflation rule gets back on track, and the paths of labor hours, consumption, and price and wage inflation are virtually identical to those obtained under the optimal policy. In contrast, the benchmark price inflation rule is overly stimulative at the onset of the shock, keeping price inflation near baseline but generating excessive nominal wage inflation.

\section{$5 \quad$ Parameter Uncertainty}

In this section, we explore the sensitivity of household welfare to variations in the parameters under the wage inflation policy rule optimized to the baseline parameters discussed in Section 3. We evaluate the performance of this rule in comparison with that of the optimal policy determined using the true values of the model parameters.

\subsection{Estimated Parameters}

We start by considering the effect of uncertainty as measured by our estimated posterior distribution. We compute the welfare losses associated with joint parameter uncertainty of the ten structural parameters together. ${ }^{45}$ For this purpose, we randomly select 5000 draws of the parameter vector from the posterior distribution described above. For each draw, we compute welfare under the optimal policy for the true set of parameters and under the benchmark wage inflation policy. Note that this method incorporates the covariance between the model parameters, allowing for the possibility that particular combinations of parameter

\footnotetext{
${ }^{45}$ We do not, however, vary the parameters associated with the shock processes or the calibrated parameters.
} 

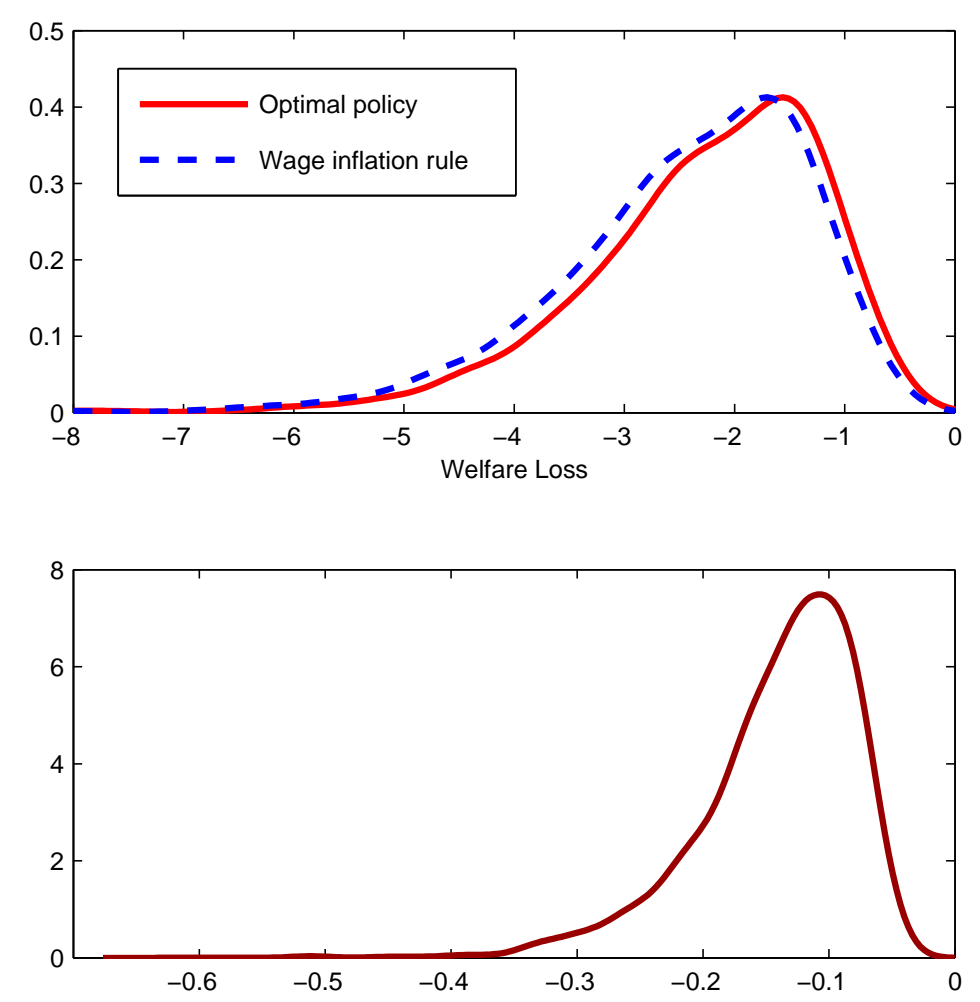

Figure 5: The distribution of welfare losses for the estimated posterior distribution. Top panel: Welfare losses relative to the steady state for the optimal policy tuned to each parameter draw (red line) and the benchmark wage inflation rule (dashed blue line) Bottom panel: Difference in welfare loss between the optimal and benchmark wage inflation rule.

realizations may have sizeable effects on outcomes. Figure 5 reports the results from this exercise; the upper panel shows the resulting distributions of welfare losses under the two policies and the lower panel shows the distribution of the relative welfare loss equal to the difference in welfare between the optimal policy and the benchmark wage inflation rule.

Uncertainty about the structural parameters implies a great deal of uncertainty regarding the welfare loss associated with fluctuations, but far less uncertainty regarding the performance of the benchmark wage inflation rule relative to the optimal policy. As seen in the upper panel of the figure, the distribution of welfare losses under either policy is wide with 
a relatively long left tail. Under the optimal policy, the median welfare loss is 2.1 percent, just 0.1 percentage point larger than for the posterior mean estimates, but the 90 percent confidence interval for the welfare loss ranges from 4.3 percent to 0.9 percent. The results under the benchmark wage inflation rule are comparable. Thus, parameter uncertainty can easily make the welfare costs of fluctuations more than double what we estimate, or, for that matter, half as large. However, as the lower panel of the figure shows, the performance of the benchmark wage inflation rule relative to the optimal policy is remarkably robust to parameter uncertainty. Indeed, the mean relative welfare loss, evaluated over the posterior distribution, is 0.14 percent, compared to 0.12 percent assuming no uncertainty, and the 90 percent probability interval for the relative welfare loss is fairly narrow, ranging from 0.06 to 0.35 percent.

Because the benchmark rule performs so well across the posterior distribution, it is not surprising that taking account of parameter uncertainty as measured by the posterior distribution has virtually no effect on the parameters or expected performance of the optimized wage inflation rule. We computed the coefficient of a wage inflation rule that maximizes expected welfare integrating over the posterior distribution as above. The optimal coefficient equals 2.9, slightly lower than the value of 3.2 in the case of no uncertainty. But, this rule yields an increase in expected welfare relative to the benchmark wage inflation rule of only 0.0004 percent. Thus, the existence of parameter uncertainty, as measured by the posterior distribution, is nearly irrelevant for designing policy in this model. Of course, a significant reduction in this uncertainty could have implications for the design of policy and welfare, as we examine next.

The degree of parameter uncertainty represented by the posterior distribution likely understates the true degree of uncertainty that policymakers face. As discussed in Onatski and N. Williams (2003) and Lubik and Schorfheide (2005), the mean and spread of the posterior distributions are highly sensitive to the assumed prior distributions. Point estimates and 
their standard errors are sensitive to estimation methodology, sample, and the values of calibrated parameters. ${ }^{46}$ This sensitivity is illustrated by the wide range of point estimates for various model parameters found in what are nearly identical models studied in CEE, SW, and this paper.

Given this concern that the degree of parameter uncertainty may exceed that implied by the posterior distribution, we now examine the robustness of the benchmark wage inflation rule to a much wider set of parameter values. A second goal of this analysis is to uncover which parameters entail costly consequences when an estimate is far from the true value. To facilitate our analysis, we vary specific parameters one at a time, holding all other parameters at their respective mean estimates. We focus our analysis on the difference in welfare between that found under the benchmark wage inflation rule and the optimal policy for the specified parameter. Again, we measure the potential loss in switching from the optimal policy (assuming the true parameter value is known) to the benchmark wage inflation rule (optimized for the baseline parameters).

We start with the parameters describing price and wage determination. Figure 6 plots the differences in the consumption-equivalent welfare losses between the optimal policy and the benchmark wage inflation rule as the four parameters related to price- and wage-setting are varied. The results for the Calvo parameters are shown in the upper panels; the results for the indexation parameters are shown in the lower panels. The vertical lines indicate the $5 \%$ and $95 \%$ posterior bounds for the parameters calculated from the MCMC simulations. If the resulting plotted line is horizontal, estimation error for that parameter has no welfare costs, while a steeply sloped line indicates that parameter estimation error carries high costs and that better estimates could have a large social benefit.

Although uncertainty regarding the wage and price parameters based on the estimated

\footnotetext{
${ }^{46}$ In addition, the welfare costs of fluctuations are very sensitive to the assumed degree of substitutability across types of labor and of goods, parameters that we take as fixed in this analysis.
} 

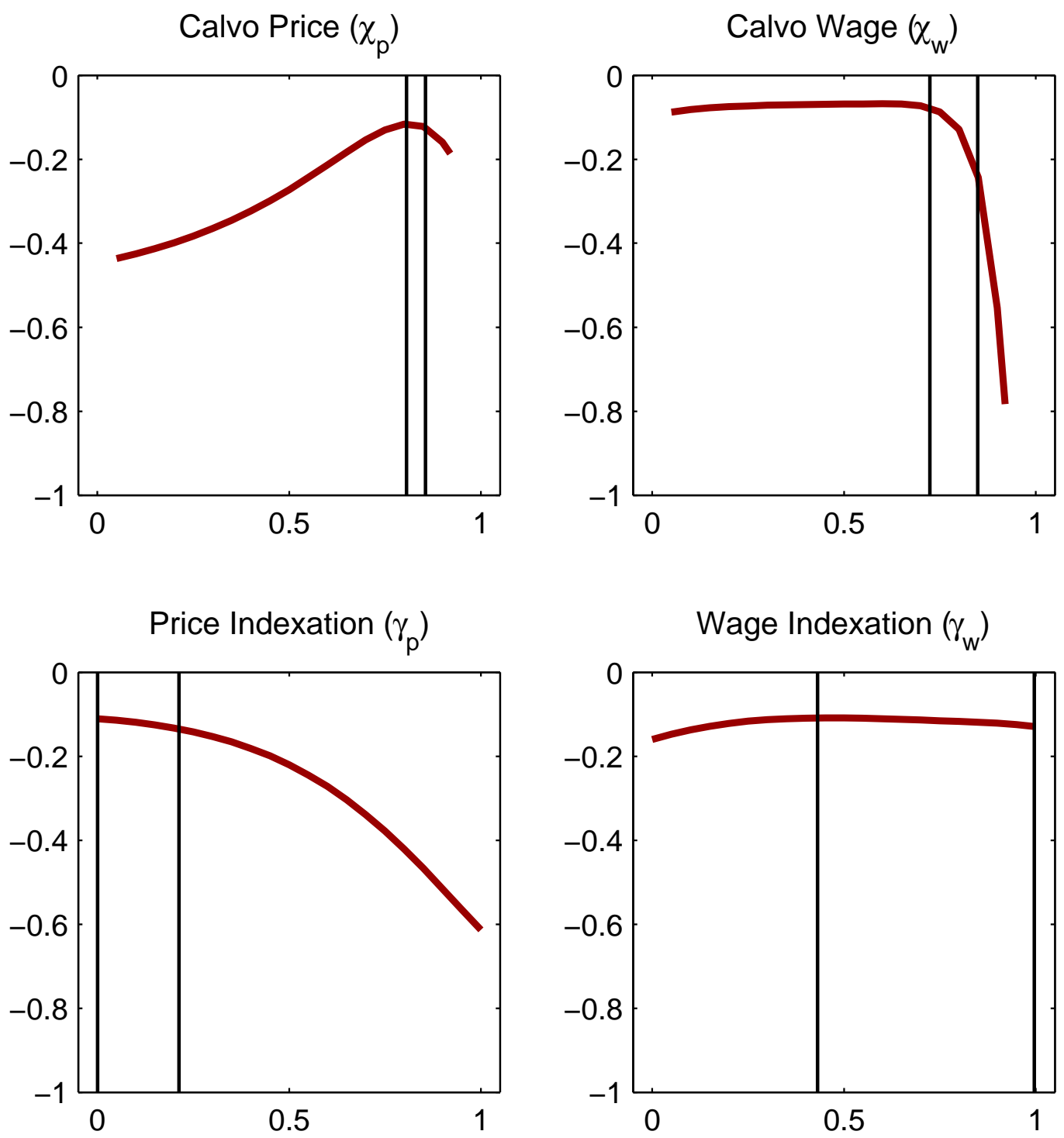

Figure 6: Parameter uncertainty: price and wage setting. The difference in welfare between the benchmark wage inflation rule and the optimal policy. The two vertical lines indicate the 5 and 95 percent bounds from the posterior distributions. 
probability intervals has very modest implications for the performance of the benchmark wage inflation rule, looked at from a broader, or an explicitly min-max, perspective, reducing uncertainty about price- and wage-setting parameters could yield moderate benefits in terms of monetary policy design and welfare. The relative performance of the benchmark wage inflation rule is sensitive to very high values of the Calvo wage parameter. For the other Calvo price and indexation parameters, the performance of the benchmark wage inflation policy drops off if prices are reoptimized very frequently or if a high share of contracts is indexed, neither of which is likely according to the posterior distribution. For example, consider the case that the true Calvo price parameter, $\xi_{p}$, is as low as some of the micro evidence suggests. According to the posterior distribution, such a low value is extremely unlikely. But, if true, knowledge of this parameter could be used to design a monetary policy that yields a moderate improvement in welfare. The same applies for the Calvo wage and price indexation parameters. Although the degree of wage indexation is imprecisely estimated, the relative welfare loss is nearly invariant to the value of this parameter.

Figure 7 plots the results for the parameters related to preferences and technology. Given the estimated precision of these parameter estimates, parameter uncertainty has trivial implications for welfare and therefore for policy. For example, although $\chi$, the parameter measuring the disutility of labor, is imprecisely estimated, it has only a modest effect on relative welfare.

It should be noted that the parameter $\phi$, which measures the degree of increasing returns, does have a significant effect on relative welfare under the benchmark wage rule. With a loose prior, we would estimate a value for this parameter near 2. Assuming that the results of the literature indicating at most modest increasing returns are true, the resulting reduction in uncertainty has a large effect on welfare in this model assuming policy is designed to be optimal at the baseline estimates. Moreover our estimate of the habit persistence parameter is on the low side of recent estimates, which tend to find values in the $0.5-0.7$ range. Once 

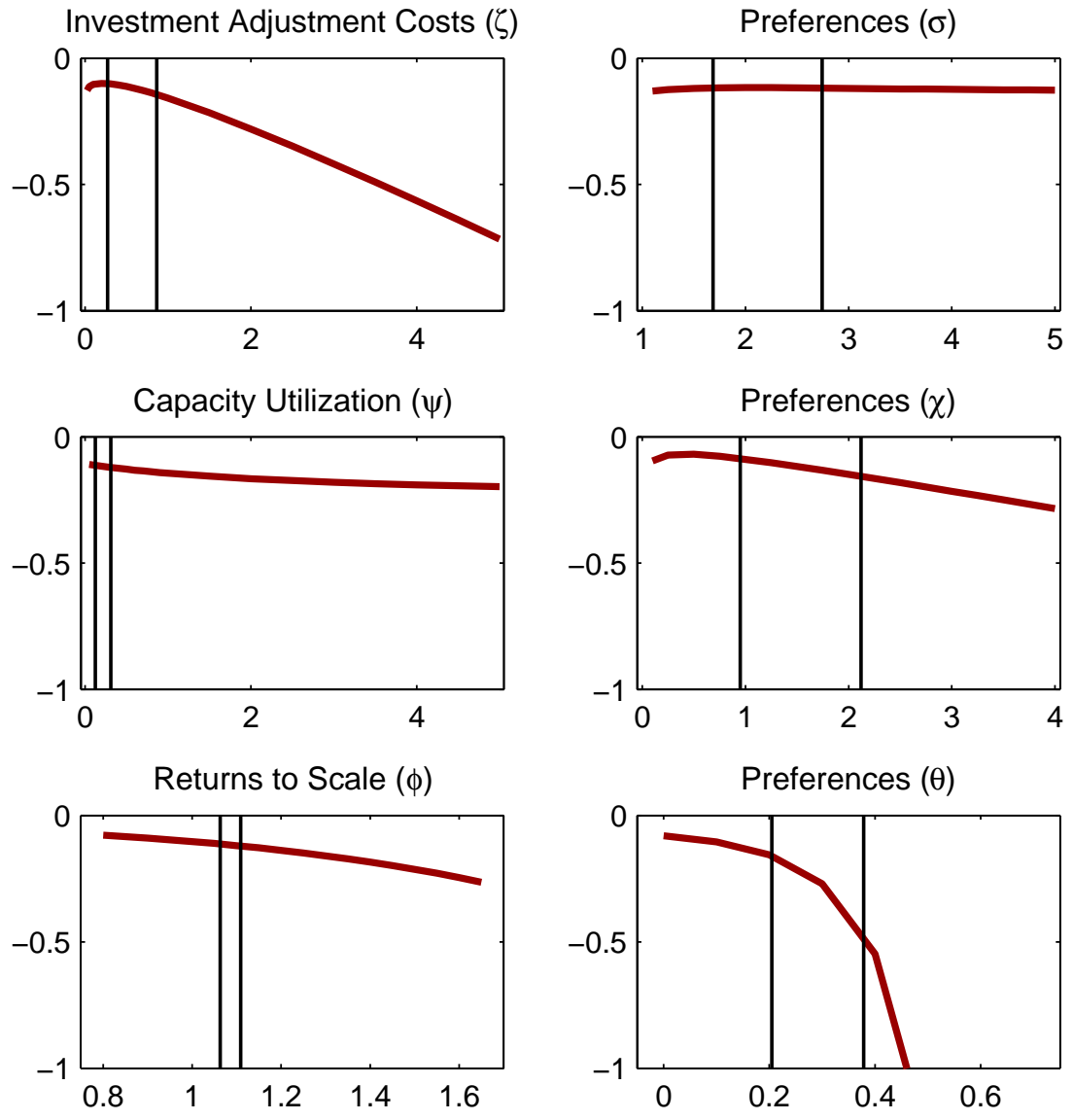

Figure 7: Parameter uncertainty: other structural parameters. The difference in welfare between the benchmark wage inflation rule and the optimal policy. The two vertical lines indicate the 5 and 95 percent bounds from the posterior distributions. 
again, we find such values to be unlikely but we find a significant drop in the performance of the benchmark wage inflation rule when the habit parameter increases past 0.5. Finally, knowledge of the true magnitude of investment adjustment costs would be valuable for policy design.

\section{$5.2 \quad$ Steady-state Markups}

As noted above, we cannot estimate the steady-state price and wage markups using the first-order dynamics of the model, but instead calibrate both to be 20 percent. Given the uncertainty regarding the values of these parameters, we briefly explore the implications of alternative calibrations of the steady-state markups for monetary policy.

The magnitude of welfare losses depends on the steady-state price markup, but the performance of the benchmark wage inflation rule relative to the optimal policy is insensitive to this parameter. We evaluate the welfare losses under four representative monetary policies analyzed above as $\lambda^{p}$ is varied from 0.1 to 0.5 , holding all other parameters fixed. Recall that the steady-state price markup does not affect the first-order properties of the system. ${ }^{47}$ The results are shown in the upper part of Table 3. Welfare losses are larger, the smaller is the steady-state price markup, reflecting the effect of greater dispersion when goods are more highly substitutable. The relative performance of the various policies is insensitive to the value of the steady-state price markup.

The welfare losses are highly sensitive to the value of the steady-state wage markup, and for very high values of this parameter, the performance of the benchmark price inflation policy rule approaches that of the benchmark wage inflation rule. In considering the effects of variations in $\lambda^{w}$, we vary the value of Calvo wage parameter, $\xi_{w}$, so that the first-order properties of the model are constant. ${ }^{48}$ We hold all other parameter values fixed at baseline

\footnotetext{
${ }^{47}$ Note that we do not impose a relationship between the fixed cost parameter and the markup implied by a zero-profit condition.

${ }^{48}$ Thus, we isolate the effects of changing the substitutability of different types of labor on welfare from
} 
Table 3: Welfare Losses and the Steady-State Markups

\begin{tabular}{lcccc}
\hline \hline Experiment & $\begin{array}{c}\text { Optimal } \\
\text { Policy }\end{array}$ & $\begin{array}{c}\text { Empirical } \\
\text { Reaction }\end{array}$ & $\begin{array}{c}\text { Benchmark Wage } \\
\text { Inflation Rule }\end{array}$ & $\begin{array}{c}\text { Benchmark Price } \\
\text { Inflation Rule }\end{array}$ \\
\hline Price markup: $\lambda^{p}$ & & & & -2.64 \\
0.10 & -2.13 & -2.72 & -2.23 & -2.60 \\
0.20 & -2.01 & -2.57 & -2.13 & -2.57 \\
0.50 & -1.92 & -2.48 & -2.07 & \\
& & & & -7.90 \\
Wage markup: $\lambda^{w}$ & & & & -4.44 \\
0.05 & -4.91 & -7.94 & -6.05 & -2.60 \\
0.10 & -3.18 & -4.43 & -3.47 & -1.45 \\
0.20 & -2.01 & -2.57 & -2.13 & \\
0.50 & -1.15 & -1.42 & -1.30 & \\
\hline \hline
\end{tabular}

values. Note that even with a high steady-state wage markup, the benchmark wage inflation policy rule performs well, although the difference between it and the rules that respond to price inflation is much smaller than in the baseline model.

\section{Innovation Uncertainty}

We now consider alternative assumptions regarding the set of shocks in the model. In computing welfare, we have had to take a stand on each shock as to whether it reflects shifts in fundamentals, the effects of distortions, or measurement error. In particular, we have assumed that the wage and price shocks and the shocks to the external finance premium are distortionary, while the remaining shocks reflect shifts in fundamentals. We now revisit these assumptions and evaluate the performance of the various monetary policies under alternative assumptions regarding the nature of innovations.

The baseline model is admittedly profligate in specifying shocks. In particular, the external finance premium has a large estimated variance and may be important for welfare according to the model, but arguably lacks microfoundations. Importantly, we have assumed those on the sensitivity of wages to movements in the marginal rate of substitution. 
Table 4: Welfare under Innovation Uncertainty

\begin{tabular}{lcccc}
\hline \hline Experiment & $\begin{array}{c}\text { Optimal } \\
\text { Policy }\end{array}$ & $\begin{array}{c}\text { Empirical } \\
\text { Reaction }\end{array}$ & $\begin{array}{c}\text { Benchmark Wage } \\
\text { Inflation Rule }\end{array}$ & $\begin{array}{c}\text { Benchmark Price } \\
\text { Inflation Rule }\end{array}$ \\
\hline Baseline specification & -2.01 & -2.57 & -2.13 & -2.60 \\
Eliminate shocks to: & & & & \\
External finance premium & -2.00 & -2.55 & -2.11 & -2.57 \\
Price markup & -1.95 & -2.51 & -2.04 & -2.48 \\
Wage markup & -0.22 & -0.44 & -0.30 & -0.65 \\
Time preference & -2.29 & -2.78 & -2.38 & -2.76 \\
Labor disutility & -2.24 & -2.79 & -2.36 & -2.79 \\
& & & & \\
Assume shocks distortionary & & & & -2.68 \\
Time preference & -2.58 & -3.35 & -2.59 & -3.08 \\
Labor disutility & -2.46 & -3.14 & & \\
\hline \hline
\end{tabular}

that this shock does not affect fundamentals, but instead represents inefficient fluctuations in an external finance premium or a type of "animal spirits" that monetary policy should counteract. We therefore consider an alternative model specification in which these shocks do not exist, that is, Tobin's Q strictly follows fundamentals. We assume that these shocks represent measurement error evident in estimating the model, but that they have no effects on the actual allocation of resources. We do no re-estimate the model, but rather simply set the variance of the external finance premium shocks to zero. ${ }^{49}$ The second line of Table 4 reports the results from this experiment. Interestingly, eliminating the external finance premium shocks has little effect on welfare or on the relative performance of the various policy rules.

We further examine how the policy rules perform under alternative assumptions regarding the nature of shocks to price and wage markups. In the baseline model, these shocks are

\footnotetext{
${ }^{49}$ In a previous version of this paper, we estimated an alternative model that included no external finance premium shocks. Estimates of most model parameters were nearly identical to the baseline estimates. Exceptions included the estimate of $\zeta$, which fell, implying significantly higher costs of adjusting investment, and the investment adjustment cost shock became more variable and less persistent. The effects on welfare of this specification were modest.
} 
viewed as being distortionary movements in markups. We now consider the possibility that these disturbances simply reflect measurement error. Again, we do not re-estimate the model, but instead simply zero out these residuals. We consider each shock in isolation and the combined effect. The results are shown in the upper part of Table 4.

Eliminating either markup shock reduces the welfare costs of fluctuations, but does not alter the relative performance of the various policy rules. In either case, the welfare gap between the optimal policy and the benchmark wage inflation rule is reduced relative to that in the baseline specification. The price shocks have relatively little effect on welfare; the wage shocks, however, are an important source of welfare loss under both the optimal and the benchmark policies but, nevertheless, have little effect on the relative performance of the benchmark wage inflation policy rule.

Finally, we consider the nature of disturbances to preferences. In the baseline model, we have assumed that shocks to time preference and the disutility of labor reflect fundamental movements in the economy that monetary policy should accommodate. We consider two alternative assumptions. First, we assume that the shocks merely reflect measurement error and evaluate the four policies under the assumption that the preference shock does not exist. As before, we consider each shock in isolation. Interestingly, eliminating either preference shock increases welfare under the various policies by about 0.25 percentage point; that is, stochastic shocks to preferences are welfare-enhancing in our baseline model. ${ }^{50}$ The performance of the benchmark wage inflation rule relative to the optimal policy is virtually unchanged. Second, we consider the assumption that the preference shocks reflect nonfundamentals, such as changes in tax rates. The results are shown in the lower section of Table 4. In this case, the welfare losses are significantly higher than in the baseline model, but, again, the performance of the benchmark wage inflation rule relative to the optimal

\footnotetext{
${ }^{50}$ Because a shock to preferences affects only welfare and not the production possibilities of the economy, with flexible wages and prices, welfare is non-decreasing to a mean-preserving spread to preferences.
} 
policy does not deteriorate.

Regardless of the assumption about the nature of these shocks, the benchmark wage inflation rule is nearly optimal and outperforms the estimated and benchmark price inflation rules by a significant margin. In summary, although innovation uncertainty exacerbates the already significant uncertainty about the magnitude of the welfare costs of fluctuations, the benchmark wage inflation rule is remarkably robust to changes in assumptions regarding the nature of shocks hitting the economy.

\section{Specification Uncertainty}

We now proceed to consider the broader problem of specification uncertainty in the sense of Leamer (1978). ${ }^{51}$ In specifying the baseline model, we made numerous choices that affect the parameter estimates, the structure of the model, and the determinants of welfare. In this section, we analyze the sensitivity of optimal policies to alternate assumptions regarding the model specification and evaluate the marginal benefit of reducing uncertainty of each of the key specification issues in terms of social welfare. As in the preceding section, this analysis provides information on the value, from the perspective of monetary policy, of improving our knowledge of specification issues and suggests where the highest payoffs are for further research in this area. While the list of specifications we consider is far from exhaustive, it provides some examples of the type of specification uncertainty that may be important for policy analysis.

\subsection{Monetary Frictions and Working Capital}

Our baseline model can be viewed as a "cashless economy" that completely abstracts from monetary frictions. We now investigate the policy implications of incorporating household

\footnotetext{
${ }^{51}$ For some early analysis of specification uncertainty in structural models, see Becker, Dwolatsky, Karakitsos, and Rustem (1986) and Frankel and Rockett (1988).
} 
demand for money as well as working-capital considerations for firms. First, we permit the scale parameter $\mu_{0}$ to have a non-trivial value, so that real money balances have direct effects on household utility. Second, following CEE, we assume that firms must borrow from financial intermediaries to cover their wage bill and then repay the loan at the end of the period. Thus, assuming that these funds can be obtained at the gross risk-free nominal interest rate, firms' total labor costs are now given by $R_{t} W_{t} L_{t}$.

Since we specify that policy is conducted via an interest rate rule, we do not need to concern ourselves with market clearing in the loan market. This would only serve to pin down the value of broad money. Instead, we simply append the portfolio allocation decision to determine the household's cash balances (which now affect welfare), and we incorporate the effects of working capital on firms' labor demand and marginal costs. We then re-estimate the model, using data on cash balances in addition to the seven variables noted above. ${ }^{52}$ The mode estimate of the preference parameter $\kappa$ is 11.4 , while the mode estimates of all other model parameters are nearly the same as in the baseline specification. ${ }^{53}$

The modified model has two key implications for policy. First, owing to the effects of nominal interest rates on costs and money balances, the optimal inflation rate is no longer zero, but instead slightly below zero. Second, there is a cost to highly variable nominal interest rates that is absent in the baseline model and a resultant benefit to smoothing interest rates. As a result, the optimal wage inflation policy rule responds less aggressively to wage inflation, with a coefficient of 1.5 , compared to 3.2 in the baseline model. ${ }^{54}$ The benchmark wage inflation rule yields a welfare loss 0.07 percentage points in terms of permanent consumption greater than a rule optimized for this alternative model with monetary frictions and working capital.

\footnotetext{
${ }^{52}$ The money data are available only from 1959 onward, so we shorten the sample by four years. Linearized expressions are again given in the appendix.

${ }^{53}$ Complete estimation results are reported in Appendix C.

${ }^{54}$ It is still the case that the optimal coefficient on price inflation is zero.
} 


\subsection{Alternative Models of Wage Setting}

A key result in our analysis is the importance of stabilizing wages owing to the distortions associated with wage dispersion under Calvo-style contracts. Given the central role of this channel, we consider alternative specifications of wage setting that have significant effects on the welfare implications of sticky wages and on optimal policy. In particular, we consider two alternative specifications in which the effects of wage dispersion on welfare are muted relative to the Calvo-style model. ${ }^{55}$

We first consider a modest modification to the indexation of wages in the model and assume that non-optimized wages are indexed to last period's wage inflation rate, as opposed to the rate of price inflation. This modification reduces the effects of fluctuations in wage inflation on wage dispersion and thereby on welfare. ${ }^{56}$ Table 4 reports the results from this specification for four specifications of monetary policy. Not surprisingly, the consumptionequivalent loss in conditional welfare under the optimal policy is somewhat smaller than in the baseline model.

The relative performance of the benchmark wage inflation rule, however, is considerably worse under this form of wage indexation and is dominated by the rule that responds only to price inflation. Under the benchmark wage inflation policy rule, the consumption-equivalent loss in conditional welfare is 0.6 percentage points larger than under the optimal policy and 0.3 percentage points higher than under the benchmark price inflation rule. In fact, with this specification of wage indexation, the benchmark wage inflation policy rule does slightlyworse than the estimated policy rule. Evidently, the result that a simple policy rule designed to maximize welfare should respond exclusively to wage inflation is not robust to changes in

\footnotetext{
${ }^{55}$ Although not considered here, another model of wage and price setting that does not yield dispersion effects on aggregate welfare is the quadratic adjustment costs model of Rotemberg (1982).

${ }^{56}$ We estimated a version of the baseline model where wage indexation depends on a combination of past price and wage inflation. We found that the weight is primarily on past price inflation, providing support for the baseline model specification. Nonetheless, one may not be convinced by this finding and remained concerned about uncertainty regarding the form of wage indexation.
} 
Table 5: Welfare under Uncertainty Regarding Wage Setting

\begin{tabular}{lcccc}
\hline \hline Experiment & $\begin{array}{c}\text { Optimal } \\
\text { Policy }\end{array}$ & $\begin{array}{c}\text { Empirical } \\
\text { Reaction }\end{array}$ & $\begin{array}{c}\text { Benchmark Wage } \\
\text { Inflation Rule }\end{array}$ & $\begin{array}{c}\text { Benchmark Price } \\
\text { Inflation Rule }\end{array}$ \\
\hline Baseline specification & -2.01 & -2.57 & -2.13 & -2.60 \\
& & & & -2.46 \\
Wage-wage indexation & -1.85 & -2.34 & -0.85 & -2.15 \\
Taylor contracts & -0.35 & -0.41 & -0.50 \\
\hline \hline
\end{tabular}

the model of wage determination, even to this seemingly innocuous change in the model specification.

We now consider a more substantive change in the specification of wage and price determination, and assume that contracts have fixed duration as in Taylor (1980); see also Chari, Kehoe, and McGrattan (2000). ${ }^{57}$ Compared with the baseline specification of Calvo-style contracts with random duration, this alternative specification limits the degree of price and wage dispersion-and the associated welfare costs-resulting from the presence of some prices and wages that have not been reoptimized for many periods.

We suppose that nominal wages and prices are determined by staggered contracts that are reset every $M$ periods. Thus at $t$ the distribution of wages is given by $\left\{W_{t, j}\right\}$ where $j=1, \ldots, M$ denotes the number of periods since the last re-set. In particular, we assume that all price and wage contracts last for four quarters, implying mean contract durations somewhat shorter than implied by our posterior mean estimates of the Calvo update parameters, $\xi_{p}$ and $\xi_{w}$. We do not change any other parameter estimates and revert to the baseline assumption that wages are indexed to past price inflation. The results are reported in Table 5. As expected, replacing Calvo-style wage and price setting with Taylor-style contracts significantly reduces wage and price dispersion and hence the welfare costs associated with fluctuations.

\footnotetext{
${ }^{57}$ As explained below, we have not formally estimated this alternative specification. The empirical performance of the model may be sensitive to which type of nominal rigidity is assumed; see Chari, Kehoe, and McGrattan (2000), Kiley (2002), and Guerrieri (2001).
} 
With Taylor-style staggered wages and prices, the relative performance of the benchmark wage inflation rule falls dramatically, while the estimated policy rule is nearly optimal. The benchmark price inflation rule outperforms the benchmark wage inflation rule, but falls behind the estimated rule. With Taylor price and wage contracts, the welfare costs associated with price and wage dispersion are relatively modest and, therefore, the optimal policy focuses on coming close to the real allocation in the flexible wage and price economy. The estimated rule accomplishes this balance very well, while the benchmark price inflation rule is somewhat less effective owing to a lack of response to the output gap. The performance of the benchmark wage inflation rule suffers more significantly because it implicitly puts far too much emphasis on stabilizing nominal wage inflation relative to achieving the flexible wage and price real allocation. ${ }^{58}$

Finally, it should be noted that the welfare cost of business cycles and the performance of alternative monetary policies are sensitive not only to the structure of nominal contracts but to the specification of household preferences. For example, as in CEE and SW, our analysis has followed Erceg, Henderson, and Levin (2000) in assuming that each individual household provides a distinct labor service, whereas Schmitt-Grohe and Uribe (this volume) assume that each household has a continuum of members providing all types of labor services and that the household's utility only depends on its total hours of work. While such assumptions might seem to be merely technical details, in fact these differences have fairly dramatic consequences for the first-order dynamics of wage inflation, the second-order effects of crosssectional wage dispersion, and the design of welfare-maximizing policy rules. ${ }^{59}$

\footnotetext{
${ }^{58}$ We also examined a version of the model with Taylor wage contracts and Calvo prices. The results were very similar to those found when both wages and prices are set by Taylor contracts.

${ }^{59}$ The specification of Erceg, Henderson, and Levin (2000) implies a much flatter nominal wage Phillips curve; that is, nominal wage inflation is much less sensitive to the marginal rate of substitution between consumption and leisure. Furthermore, cross-sectional wage dispersion induces differences in labor across households that have substantial effects on social welfare.
} 


\section{Conclusion}

Over the past decade there has been remarkable progress in developing empirical microfounded macroeconomic models for monetary policy analysis. In this paper we have drawn on and extended this literature to consider the design of policy under uncertainty. By confronting a fully-specified dynamic stochastic general equilibrium model with the data, we can directly gauge the uncertainty associated with the model parameters as well as the implications of alternative assumptions about the model specification.

Our analysis indicates that the welfare cost of business cycles is quite large-an order of magnitude larger than the findings emphasized by Lucas (2003)-and arises mainly due to inefficiencies associated with cross-sectional dispersion in wages and employment. As a direct consequence, we find that the welfare outcome associated with optimal policy under commitment is closely matched by a very simple rule that responds solely to nominal wage inflation. Furthermore, the performance of this benchmark wage inflation rule is remarkably robust to uncertainty about the structural parameters and the particular shocks hitting the economy. The performance of this rule $i s$ very sensitive to the specification of wage and price determination, suggesting that a hybrid rule involving both wage and price inflation might be more robust across a broader class of models.

These findings underscore the central importance of labor markets for analyzing the welfare costs of macroeconomic fluctuations and the design of monetary policy. Of course, the crucial role of wage setting and employment dynamics has long been recognized, and recent research has refocused interest on these issues; see Hall (2005). Thus, further progress in formulating micro-founded specifications of labor market behavior and comparing the empirical performance of these specifications is likely to have substantial payoffs for the design of monetary policy.

Finally, while our analysis has emphasized the implications of policymaker uncertainty 
regarding the true structure of the economy, we have abstracted completely from the role of learning by policymakers or private agents. Nevertheless, we recognize that the learning mechanism is crucial for understanding the evolution of the economy in response to changes in the monetary policy regime-such as the Volcker disinflation-and to other aggregate disturbances. ${ }^{60}$ Thus, incorporating learning in micro-founded macroeconometric models and reconsidering the policy implications represents a natural direction for future research. ${ }^{61}$

\footnotetext{
${ }^{60}$ Erceg and Levin (2003) analyze a DGE model roughly similar to the one in this paper and show that private agents' gradual learning about the Fed's inflation objective is crucial for interpreting the effects of the Volcker disinflation, while Edge, Laubach, and J. Williams (2003) and Erceg, Guerrieri, and Gust (2005) highlight the role of learning in fitting the stylized facts of the U.S. productivity growth boom of the late 1990s.

${ }^{61}$ See Beck and Wieland (2002) for analysis of optimal learning and control in a small stylized economy with ongoing structural change.
} 


\section{References}

Altig, D., L. J. Christiano, M. Eichenbaum, and J. Linde (2004). Firm-specific capital, nominal rigidities and the business cycle. Mimeo.

Angeloni, I., L. Aucremanne, M. Ehrmann, J. Gali, A. T. Levin, and F. Smets (2004). Inflation persistence in the euro area: Preliminary summary of findings. manuscript, European Central Bank.

Aoki, K. (2003). On the optimal monetary policy response to noisy indicators. Journal of Monetary Economics 50, 501-523.

Basu, S. (1996). Procyclical productivity: Increasing returns or cyclical utilization? Quarterly Journal of Economics 111, 719-51.

Basu, S. and J. G. Fernald (1997). Returns to scale in U.S. production: Estimates and implications. Journal of Political Economy 105, 249-83.

Basu, S. and M. Kimball (2003). Investment planning costs and the effects of fiscal and monetary policy. manuscript, University of Michigan.

Beck, G. W. and V. Wieland (2002). Learning and control in a changing economic environment. Journal of Economic Dynamics and Control 26, 1359-1377.

Becker, R. G., B. Dwolatsky, E. Karakitsos, and B. Rustem (1986). The simultaneous use of rival models in policy optimisation. Economic Journal 96, 425-48.

Benigno, P. and M. D. Woodford (2004). Optimal stabilization policy when wages and prices are sticky: The case of a distorted steady state. NBER working paper no. 10839.

Bernanke, B. S. and J. J. Rotemberg (Eds.) (1997). NBER Macroeconomics Annual 1997. Cambridge: MIT Press for the NBER.

Bernanke, B. S. and M. Woodford (Eds.) (2005). The Inflation-Targeting Debate. University of Chicago Press.

Bils, M. and P. Klenow (2004). Some evidence on the importance of sticky prices. Journal of Political Economy 112, 947-985.

Boldrin, M., L. J. Christiano, and J. D. M. Fisher (2001). Habit persistence, asset returns, and the business cycle. American Economic Review 91, 149-66.

Brainard, W. (1967). Uncertainty and the effectiveness of policy. American Economic Review 5\%, 411-425.

Brock, W. A., S. N. Durlauf, and K. D. West (2003). Policy evaluation in uncertain economic environments. Brookings Papers on Economic Activity, 235-301.

Calvo, G. (1983). Staggered prices in a utility-maximizing framework. Journal of Monetary Economics A12, 383-398.

Canzoneri, M., R. Cumby, and B. Diba (2004). The cost of nominal inertia in new neoclassical synthesis models. Manuscript, Georgetown University. 
Chari, V. V., P. J. Kehoe, and E. R. McGrattan (2000). Sticky price models of the business cycle: Can the contract multiplier solve the persistence problem? Econometrica 68, 1151-1179.

Cho, J.-O., T. F. Cooley, and L. Phaneuf (1997, July). The welfare cost of nominal wage contracting. Review of Economic Studies 64, 465-484.

Christiano, L., M. Eichenbaum, and C. Evans (2005). Nominal rigidities and the dynamic effects of a shock to monetary policy. Journal of Political Economy 113, 1-45.

Christiano, L. J., R. Motto, and M. Rostagno (2004). The Great Depression and the Friedman-Schwartz hypothesis. NBER Working Paper No. w10255.

Clarida, R., J. Gali, and M. Gertler (1999). The science of monetary policy: a new keynesian perspective. Journal of Economic Literature 37, 1661-1707.

Coenen, G. and A. T. Levin (2004). Identifying nominal and real rigidities in aggregate price-setting behavior. European Central Bank Working Paper.

Craine, R. (1979). Optimal monetary policy with uncertainty. Journal of Economic Dynamics and Control 1, 59-83.

Croushore, D. and T. Stark (2003). A real-time data set for macroeconomists: Does the data vintage matter? Review of Economics and Statistics 85, 605-617.

Del Negro, M. and F. Schorfheide (2004). Priors from general equilibrium models for VARs. International Economic Review 45, forthcoming.

del Negro, M., F. Schorfheide, F. Smets, and R. Wouters (2004). On the fit and forecasting performance of new keynesian models. Manuscript, Federal Reserve Bank of Atlanta.

Dhyne, E., L. Alvarez, H. L. Bihan, G. Veronese, D. Dias, J. Hoffmann, N. Jonker, P. Lnnemann, F. Rumler, and J. Vilmunen (2005). Price setting in the euro area: Some stylised facts from individual consumer price data. manuscript, European Central Bank.

Dynan, K. (2000). Habit formation in consumer preferences: Evidence from panel data. American Economic Review 90, 391-406.

Edge, R. M., T. Laubach, and J. Williams (2003). The responses of wages and prices to technology shocks. Federal Reserve Bank of San Francisco, Working Papers in Applied Economic Theory: 2003-21.

Eggertsson, G. B. and M. Woodford (2003). The zero bound on interest rates and optimal monetary policy. Brookings Papers on Economic Activity, 139-233.

Eichenbaum, M. and J. Fisher (2004). Evaluating the calvo model of sticky prices. NBER Working Paper 10617.

Erceg, C. J., L. Guerrieri, and C. Gust (2005). Sigma: A new open economy model for policy analysis. International Finance Discussion Paper No. 835, Board of Governors of the Federal Reserve System. 
Erceg, C. J., D. W. Henderson, and A. T. Levin (2000). Optimal monetary policy with staggered wage and price contracts. Journal of Monetary Economics 46, 281-313.

Erceg, C. J. and A. T. Levin (2003). Imperfect credibility and inflation persistence. Journal of Monetary Economics 50, 915-944.

Erceg, C. J. and A. T. Levin (2005). Optimal monetary policy with durable consumption goods. Journal of Monetary Economics, Forthcoming.

Frankel, J. A. and K. Rockett (1988). International macroeconomic policy coordination when policymakers do not agree on the true model. American Economic Review 78, 318-40.

Fuhrer, J. C. (2000). Habit formation in consumption and its implications for monetarypolicy models. American Economic Review 90, 67-90.

Gali, J., M. Gertler, and J. Lopez-Salido (2001). European inflation dynamics. European Economic Review 45, 1237-1270.

Gelman, A., J. B. Carlin, H. S. Stern, and D. R. Rubin (2004). Bayesian Data Analysis (Second ed.). Boca Raton: Chapman \& Hall.

Giannoni, M. (2002). Does model uncertainty justify caution? Robust optimal monetary policy in a forward-looking model. Macroeconomic Dynamics 6, 111-144.

Giannoni, M. and M. Woodford (2004). Optimal inflation targeting rules. See Bernanke and Woodford (2005).

Golosov, M. and R. Lucas (2003). Menu costs and Phillips curves. NBER working paper.

Goodfriend, M. and R. King (1997). The new neoclassical synthesis and the role of monetary policy. See Bernanke and Rotemberg (1997), pp. 231-283.

Greenspan, A. (2003). Opening remarks at "Monetary Policy Under Uncertainty", A symposium sponsored by the Federal Reserve Bank of Kansas City, Jackson Hole, Wyoming.

Griffin, P. (1996a). The impact of affirmative action on labor demand: a test of some implications of the le chatelier principle. Review of Economics and Statistics 74, 251260.

Griffin, P. (1996b). Input demand elasticities for heterogeneous labor: firm-level estimates and an investigation into the effects of aggregation. Southern Economic Journal 62, 889-901.

Guerrieri, L. (2001). Inflation dynamics. Board of Governors of the Federal Reserve System International Finance Discussion Papers Number 715.

Guvenen, F. (2005). Reconciling conflicting evidence on the elasticity of intertemporal substitution. Journal of Monetary Economics, forthcoming.

Hall, R. E. (2005). Job loss, job finding, and unemployment in the U.S. economy over the past fifty years. Working paper for 2005 NBER Macroannual. 
Hansen, L. P. and T. J. Sargent (2003). Robust Control and Econmic Model Uncertainty. Mimeo. University of Chicago.

Huang, K. X. and Z. Liu (2004). Input-output structure and nominal rigidity: the persistence problem revisited. Macroeconomic Dynamics 8, 188-206.

Ireland, P. (2001). Sticky-price models of the business cycle: Specification and stability. Journal of Monetary Economics 47, 3-18.

Judd, J. P. and G. D. Rudebusch (1998). Taylor's rule and the Fed: 1970-1997. Federal Reserve Bank of San Francisco Economic Review 0, 3-16.

Judd, K. (1998). Numerical Methods in Economics. Cambridge, MA: MIT Press.

Juillard, M. (2001). Dynare: A program for solving and estimating rational expectation models. http://www.cepremap.cnrs.fr/dynare.

Khan, A., R. King, and A. Wolman (2003). Optimal monetary policy. Review of Economic Studies 60, 825-860.

Kiley, M. T. (2002). Partial adjustment and staggered price setting. Journal of Money, Credit, and Banking 34, 283-98.

Kim, J. and S. Kim (2003). Spurious welfare reversals in international business cycle models. Journal of International Economics 60, 471-500.

Kim, J., S. Kim, E. Schaumburg, and C. Sims (2003). Calculating and using second order accurate solutions of discrete time dynamic equilibrium models. Mimeo.

Kimball, M. S. (1995). The quantitative analytics of the basic neomonetarist model. Journal of Money, Credit and Banking 27, 1241-1277.

Kimura, T. and T. Kurozumi (2003). Optimal monetary policy in a microfounded model with parameter uncertainty. Manuscript, Bank of Japan.

King, R. and S. Rebelo (1999). Resuscitating Real Business Cycles. See Taylor and Woodford (1999), pp. 927-1007.

King, R. and A. Wolman (1999). What should the monetary authority do when prices are sticky? See Taylor (1999a), pp. 349-398.

Klenow, P. and O. Kryvtsov (2004). State-dependent or time-dependent pricing: Does it matter for recent us inflation. Mimeo, Stanford University.

Kydland, F. and E. Prescott (1980). Dynamic optimal taxation, rational expectations, and optimal control. Journal of Economic Dynamics and Control 2, 79-91.

Laforte, J.-P. (2003). Comparing monetary policy rules in an estimated equilibrium model of the US economy. Mimeo.

Leamer, E. E. (1978). Specification Searches: Ad Hoc Inference with Non Experimental Data. John Wiley and Sons, Inc.

Levin, A. T. (1989). The theoretical and empirical relevance of staggered wage contract models. Ph.D. Dissertation, Stanford University. 
Levin, A. T. and J. Williams (2003). Robust monetary policy with competing reference models. Journal of Monetary Economics 50, 945-975.

Levin, A. T. and J. Williams (2004). Parameter uncertainty and the central bank's objective function. manuscript.

Levin, A. T. and D. Lopez-Salido (2004). Optimal monetary policy with endogenous capital accumulation. manuscript.

Levin, A. T., F. M. Natalucci, and E. Zakrajsek (2004). The magnitude and cyclical behavior of financial market frictions. Federal Reserve Board Finance and Economics Discussion Series Working Paper No. 2004-70.

Levin, A. T. and J. M. Piger (2004). Is inflation persistence intrinsic in industrial economies? European Central Bank Working Paper No. 334.

Levin, A. T., V. Wieland, and J. Williams (1999). Robustness of simple monetary policy rules under model uncertainty. See Taylor (1999a).

Levin, A. T., V. Wieland, and John C. Williams (2003). The performance of forecastbased monetary policy rules under model uncertainty. American Economic Review 93, 622-645.

Lubik, T. and F. Schorfheide (2005). A Bayesian Look at the New Open Economy Macroeconomics. Working paper for 2005 NBER Macroannual.

Lucas, R. E. (1976). Econometric policy evaluation: A critique. Carnegie-Rochester Conference Series on Public Policy 1, 19-46.

Lucas, R. E. (2003). Macroeconomic priorities. American Economic Review 93, 1-14.

Mankiw, N. G. and R. Reiss (2002). Sticky information versus sticky prices: a proposal to replace the new keynesian phillips curve. Quarterly Journal of Economics 117, 12951328.

McCallum, B. T. (1988). Robustness properties of a rule for monetary policy. CarnegieRochester Conference Series on Public Policy 29, 175-203.

McCallum, B. T. (1999). Issues in the Design of Monetary Policy Rules. See Taylor and Woodford (1999), pp. 1483-1530.

McCallum, B. T. and E. Nelson (1999). Performance of operational policy rules in an estimated semi-classical structural model. See Taylor (1999a), pp. 15-45.

Onatski, A. (2000). Robust monetary policy under model, data, and shock uncertainty in a forward-looking model of the US economy. Manuscript, Harvard University.

Onatski, A. and N. Williams (2003). Modeling model uncertainty. Journal of the European Economic Association 1, 1087-1122.

Onatski, A. and N. Williams (2004). Empirical and policy performance of a forwardlooking monetary model. Mimeo. 
Onatski, A. and J. H. Stock (2002). Robust monetary policy under model uncertainty in a small model of the US economy. Macroeconomic Dynamics 6, 85-110.

Orphanides, A. (2001). Monetary policy rules based on real-time data. American Economic Review 91, 964-985.

Orphanides, A. and J. C. Williams (2002). Robust monetary policy rules with unknown natural rates. Brookings Papers on Economic Activity, 63-145.

Orphanides, A. and J. C. Williams (2005). Imperfect knowledge, inflation expectations and monetary policy. See Bernanke and Woodford (2005).

Paustian, M. (2004). Can wage and price stickiness account for sizeable costs of business cycle fluctuations? Manuscript, Bonn Graduate School of Economics.

Rabanal, P. and J. Rubio-Ramirez (2003). Comparing new keynesian models of the business cycle: A bayesian approach. Federal Reserve Bank of Atlanta Working Paper 2001-22a.

Reifschneider, D. and J. C. Williams (2000, November). Three lessons for monetary policy in a low inflation era. Journal of Money, Credit and Banking 32, 936-66.

Rotemberg, J. J. (1982). Sticky prices in the United States. Journal of Political Economy 90, 1187-1211.

Rotemberg, J. J. and M. Woodford (1997). An optimization-based econometric framework for the evaluation of monetary policy. See Bernanke and Rotemberg (1997), pp. 297346.

Rotemberg, J. J. and M. Woodford (1999). Interest rate rules in an estimated sticky-price model. See Taylor (1999a).

Rudebusch, G. D. (2001, May). Is the Fed too timid? Monetary policy in an uncertain world. Review of Economics and Statistics 83, 203-217.

Sack, B. (1998). Uncertainty, learning, and gradual monetary policy. Finance and Economics Discussion Series Working Paper No. 1998-34, Board of Governors of the Federal Reserve System.

Sbordone, A. (2002). Prices and unit labor costs: A new test of price stickiness. Journal of Monetary Economics 49, 265-292.

Schmitt-Grohé, S. and M. Uribe (2004). Optimal operational monetary policy in the Christiano-Eichenbaum-Evans model of the US business cycle. Mimeo, Duke University.

Schorfheide, F. (2000). Loss function-based evaluation of DSGE models. Journal of Applied Econometrics 15, 645-670.

Shapiro, M. D. (1987). Measuring market power in U.S. industry. NBER Working Paper 2212. 
Smets, F. and R. Wouters (2003a). An estimated dynamic stochastic general equilibrium model of the Euro area. Journal of the European Economic Association 1, 1123 - 1175.

Smets, F. and R. Wouters (2003b). Shocks and frictions in US business cycles: A Bayesian DSGE approach. Mimeo.

Soderstrom, U. (2002). Monetary policy with uncertain parameters. Scandinavian Journal of Economics 104, 125-145.

Sveen, T. and L. Weinke (2004). New perspectives on capital and sticky prices. Norges Bank Working Paper 2004-3.

Svensson, L. E. and M. Woodford (2004). Implementing optimal policy through inflationforecast targeting. See Bernanke and Woodford (2005).

Svensson, L. E. O. and M. Woodford (2003). Indicator variables for optimal policy. Journal of Monetary Economics 50, 691-720.

Taylor, J. B. (1980). Aggregate dynamics and staggered contracts. Journal of Political Economy 88, 1-22.

Taylor, J. B. (1993a). Discretion versus policy rules in practice. Carnegie-Rochester Conference Series on Public Policy 39, 195-214.

Taylor, J. B. (1993b). Macroeconomic Policy in a World Economy. New York: W. W. Norton \& Company.

Taylor, J. B. (Ed.) (1999a). Monetary Policy Rules. Chicago: University of Chicago Press for the NBER.

Taylor, J. B. (1999b). Staggered price and wage setting in macroeconomics. See Taylor and Woodford (1999), pp. 1009-1050.

Taylor, J. B. and M. Woodford (Eds.) (1999). Handbook of Macroeconomics. Amsterdam: North-Holland.

Tetlow, R. J. and P. von zur Muehlen (2002). Avoiding Nash inflation: Bayesian and robust responses to model uncertainty. Finance and Economics Discussion Series, Federal Reserve Board.

Walsh, C. (2005). Endogenous objectives and the evaluation of targeting rules for monetary policy. Journal of Monetary Economics, Forthcoming.

Williams, J. C. (2003). Simple rules for monetary policy. Federal Reserve Bank of San Francisco Economic Review, 1-12.

Woodford, M. D. (2003). Interest and Prices: Foundations of a Theory of Monetary Policy. Princeton: Princeton University Press.

Woodford, M. D. (2005). Firm-specific capital and the New-Keynesian Phillips curve. International Journal of Central Banking. forthcoming.

Yun, T. (1996). Nominal price ridigity, money supply endogeneity, and business cycles. Journal of Monetary Economics 37, 345-370. 


\section{Appendix}

\section{A The Nonlinear Model}

\section{A.1 The Baseline Model}

The text describes the household side, and we now fill in some detail on the firm side. Define the capacity utilization cost function from (5) by:

$$
\Psi\left(U_{t}\right)=\mu \frac{U_{t}^{1+\psi^{-1}}}{1+\psi^{-1}},
$$

where $\psi$ is the inverse of the elasticity of utilization cost with respect to utilization, and $\mu$ is chosen so that steady state utilization costs are zero. Also define the investment adjustment cost function from (4) by:

$$
S\left(Z_{t}^{I} I_{t}(i) / I_{t-1}(i)\right)=\zeta^{-1} \frac{1}{2}\left(Z_{t}^{I} \frac{I_{t}(i)}{I_{t-1}(i)}-1\right)^{2}
$$

Note that adjustment costs are assumed to be zero at the steady state, $S(1)=0$, and are only of second-order at the steady state. by

Index households by $h$ and firms by $i$. Then denote by $N_{t}(i)$ plant $i^{\prime} s$ labor input given

$$
N_{t}(i)=\left[\int_{0}^{1} L_{t}(i, h)^{\frac{1}{1+\lambda_{t}^{w}}} d h\right]^{1+\lambda_{t}^{w}},
$$

where $L_{t}(i, j)$ is the input of labor of type $j$ at plant $i$. The plant's output is given by (3).

Aggregate final good output, $Y_{t}$ is created by (costlessly) combining a continuum of intermediate goods, $Y_{t}(i)$, indexed by $i$ :

$$
Y_{t}=\left[\int_{0}^{1} Y_{t}(i)^{\frac{1}{1+\lambda_{t}^{p}}} d i\right]^{1+\lambda_{t}^{p}} .
$$

Final goods output is equal to consumption, aggregate investment, $I_{t}$, government spending, $G_{t}$, and capital utilization costs:

$$
Y_{t}=C_{t}+G_{t}+I_{t}+\Psi\left(U_{t}\right) K_{t-1}
$$

\section{A.2 Equilibrium Allocation and Prices}

In the following, we omit household and plant indices where no confusion will result. The household's budget constraint is standard and households trade in a complete market to allocate their consumption over time. Let $M U C_{t}$ denote the marginal utility associated with 
an incremental increase in consumption in period $t$, accounting for its effect on period utility in the period $t+1$ :

$$
M U C_{t}=Z_{t}^{b}\left(C_{t}-\theta C_{t-1}\right)^{-\sigma}-\beta \theta E_{t} Z_{t+1}^{b}\left(C_{t+1}-\theta C_{t}\right)^{-\sigma} .
$$

The consumption Euler equation summarizes the representative household's optimal saving behavior:

$$
M U C_{t}=E_{t}\left[M U C_{t+1} R_{t} P_{t} / P_{t+1}\right]
$$

where $R_{t}$ is the gross nominal interest rate and $P_{t}$ is the price level.

Households set wages subject to their individual labor demand curves, which arise from the firms' input demands. The evolution of the aggregate nominal wage index is:

$$
W_{t}^{-1 / \lambda_{t}^{w}}=\xi_{w} W_{t-1}^{-1 / \lambda_{t}^{w}}\left(\frac{P_{t-1}}{P_{t-2}}\right)^{-\gamma_{w} / \lambda_{t}^{w}}+\left(1-\xi_{w}\right) \tilde{w}_{t}^{-1 / \lambda_{t}^{w}}
$$

Here $\tilde{w}_{t}$ is the optimal nominal wage chosen by those households that can optimize in the period, which satisfies:

$$
\frac{\tilde{w}_{t}}{P_{t}} E_{t} \sum_{i=0}^{\infty} \beta_{t+i}^{i} \xi_{w}^{i} L_{t+i}(h) \epsilon_{t+i}^{b}\left[\left(\frac{P_{t} P_{t+i-1}}{P_{t-1} P_{t+i}}\right)^{\gamma_{w}} \frac{M U C_{t+i}}{1+\lambda_{t+i}^{w}}-Z_{t}^{L}\left(L_{t+i}(h)\right)^{\chi}\right]=0 .
$$

As in usual in Calvo pricing models, (12) incorporates forward-looking expectations of future nominal wages, but now includes lagged inflation via the partial indexation.

Households own the capital stock, $K_{t}$, which they accumulate using the capital accumulation technology and rent to firms at rental rate $R_{t}^{k}$. This leads to three key relationships. First, we let $Q_{t}$ be the real share value per unit of capital, which is determined by an asset pricing Euler equation from (10):

$$
Q_{t}=Z_{t}^{q} E_{t}\left[\beta \frac{M U C_{t+1}}{M U C_{t}}\left(Q_{t+1}(1-\delta)+U_{t+1} R_{t+1}^{k}-\Psi\left(U_{t+1}\right)\right)\right],
$$

where $Z_{t}^{q}$ is the i.i.d. external finance premium shock. The optimal investment decision leads to an investment Euler equation:

$$
1-Q_{t} S^{\prime}\left(\frac{Z_{t}^{I} I_{t}}{I_{t-1}}\right) \frac{Z_{t}^{I} I_{t}}{I_{t-1}}=E_{t}\left[\frac{M U C_{t+1}}{M U C_{t}} Q_{t+1} S^{\prime}\left(\frac{Z_{t+1}^{I} I_{t+1}}{I_{t}}\right) \frac{Z_{t+1}^{I} I_{t+1}}{I_{t}} \frac{I_{t+1}}{I_{t}}\right]
$$

This equation balances the costs and benefits of investment, with lagged investment and the shocks showing up through the effects of the costs of adjustment. Finally, the first order condition for utilization gives:

$$
R_{t}^{k}=\Psi^{\prime}\left(U_{t}\right)
$$

On the production side, the firms' cost-minimization conditions are symmetric and given 
by:

$$
\frac{W_{t} L_{t}}{R_{t}^{k} U_{t} K_{t-1}}=\frac{1-\alpha}{\alpha}
$$

Thus, firms equate the marginal rate of transformation between labor and effective capital $\left(U_{t} K_{t-1}\right)$ to the relative factor prices, and the capital-labor ratio is identical across firms. Marginal costs are then given by:

$$
M C_{t}=\frac{W_{t}^{1-\alpha}\left(R_{t}^{k}\right)^{\alpha}}{A_{t}} \alpha^{-\alpha}(1-\alpha)^{\alpha-1} .
$$

The evolution of the aggregate nominal price index is:

$$
P_{t}^{-1 / \lambda_{t}^{f}}=\xi_{p} P_{t-1}^{-1 / \lambda_{t}^{f}}\left(\frac{P_{t-1}}{P_{t-2}}\right)^{-\gamma_{p} / \lambda_{t}^{f}}+\left(1-\xi_{p}\right) \tilde{p}_{t}^{-1 / \lambda_{t}^{f}}
$$

Here $\tilde{p}_{t}$ is the optimal price chosen by those firms that can optimize in the period, which satisfies:

$$
E_{t} \sum_{s=0}^{\infty} \beta_{t+s}^{s} \xi_{p}^{s} \lambda_{t+s}^{p} Y_{t+s}(i) M U C_{t+i}\left[\frac{\tilde{p}_{t}}{P_{t}}\left(\frac{P_{t} P_{t+s-1}}{P_{t-1} P_{t+s}}\right)^{\gamma_{p}}-\left(1+\lambda_{t+s}^{p}\right) \frac{M C_{t+s}}{P_{t+s}}\right]=0 .
$$

Finally, we close the model by specifying an empirical monetary policy reaction function. We specify policy in terms of a generalized Taylor-type rule, where the policy authority sets nominal rates in response to inflation and the output gap. To do this, we define a model-consistent output gap as the difference between actual and potential output, where potential output is defined as what would prevail under flexible prices and wages and in the absence of the three "cost-push" shocks $\left(Z_{t}^{w}, Z_{t}^{p}, Z_{t}^{q}\right)$ that cause variations in wage and price markups and the external finance premium. Thus the model is supplemented with flexible-price versions of the key equations (10)-(18) which determine potential output $Y_{t}^{*}$. Then the policy rule is assumed to take the following form:

$$
\begin{aligned}
r_{t}= & r_{i} r_{t-1}+\left(1-r_{i}\right)\left(\bar{\pi}_{t}+r_{\pi}\left(\pi_{t-1}-\pi_{t-1}^{*}\right)+r_{y} \log \left(Y_{t-1} / Y_{t-1}^{*}\right)\right) \\
& +r_{\Delta \pi}\left(\pi_{t}-\pi_{t-1}\right)+r_{\Delta y}\left\{\log \left(Y_{t} / Y_{t}^{*}\right)-\log \left(Y_{t-1} / Y_{t-1}^{*}\right)\right\}+\eta_{t}^{r}
\end{aligned}
$$

Here $r_{t}=\log R_{t}$ is the short-term interest rate, $\pi_{t}=\Delta \ln \left(P_{t} / P_{t-1}\right)$ is the inflation rate, $\pi_{t}^{*}$ is an $A R(1)$ shock to the inflation objective, and $\eta_{t}^{R}$ is an i.i.d. policy shock. 


\section{A.3 The Model with Monetary Frictions}

In the model with monetary frictions from Section 7.1, the household also has a portfolio allocation decision. The first-order condition is:

$$
Z_{t}^{b} \epsilon_{t}^{m}\left(M_{t} / P_{t}\right)^{-\kappa}=\left(R_{t}-1\right) M U C_{t} .
$$

The cost-minimization condition (16) now becomes:

$$
\frac{R_{t} W_{t} L_{t}}{R_{t}^{k} U_{t} K_{t-1}}=\frac{1-\alpha}{\alpha} .
$$

In turn, the marginal cost changes from (17) to:

$$
M C_{t}=\frac{\left(R_{t} W_{t}\right)^{1-\alpha}\left(R_{t}^{k}\right)^{\alpha}}{A_{t}} \alpha^{-\alpha}(1-\alpha)^{\alpha-1} .
$$

Market clearing in the loan market then implies:

$$
W_{t} L_{t}=A_{t}-M_{t},
$$

where $A_{t}$ represents the level of broad money after the infusion of money via the central bank.

\section{A.4 The Model with Staggered Contracts}

In the model with staggered contracts from Section 7.2, we must make a few alterations to the model. We again allow for partial indexation, so the evolution of an individual household's wage is given by:

$$
\begin{aligned}
W_{t, j} & =\left(\frac{P_{t-1}}{P_{t-2}}\right)^{\gamma_{p}} W_{t-1, j-1} \text { if } j \neq M \\
& =\tilde{w}_{t} \text { if } j=M .
\end{aligned}
$$

The aggregate wage index changes from (11) to:

$$
W_{t}^{-1 / \lambda_{t}^{w}}=\frac{1}{M} \sum_{j=1}^{M} W_{t, j}^{-1 / \lambda_{t}^{w}}
$$

Finally, the optimal wage choice satisfies:

$$
\frac{\tilde{w}_{t}}{P_{t}} E_{t} \sum_{i=0}^{M-1} \beta_{t+i}^{i} L_{t+i}(h)\left[\left(\frac{P_{t} P_{t+i-1}}{P_{t-1} P_{t+i}}\right)^{\gamma_{w}} \frac{M U C_{t+i}}{1+\lambda_{t+i}^{w}}-\epsilon_{t}^{L}\left(L_{t+i}(h)\right)^{\chi}\right]=0 .
$$




\section{B The Linearized Model}

\section{B.1 Baseline Model}

For much of the paper we work with the log-linearized version of the model described above, which we present here. We use lower-case letters to indicate the logarithmic deviations from steady state. In the case of shocks, $\epsilon_{t}^{x}$ and $\eta_{t}^{x}$ refer to the shocks normalized to the log-linear equations, with the $\epsilon$ shocks being persistent and the $\eta$ shocks i.i.d.

To save on notation, we define $\bar{R}^{k}$ as the mean real rate of return on capital which is assumed to satisfy $\beta=1 /\left(1-\delta+\bar{R}^{k}\right)$, and $\phi$ equals 1 plus the share of fixed costs in production. Furthermore, we denote $c_{y}, g_{y}$, and $k_{y}$ as the steady-state ratios of consumption, government spending, and capital to output, respectively.

The following ten equations in ten endogenous variables $\left\{c_{t}, i_{t}, q_{t}, k_{t}, r_{t}^{k}, u_{t}, l_{t}, y_{t}, w_{t}, \pi_{t}\right\}$ are the linearized counterparts to the equations described in Section A of this appendix:

$$
\begin{aligned}
c_{t} & =E_{t} \frac{1}{1+\theta+\beta \theta^{2}}\left\{\theta c_{t-1}+\left(1+\beta \theta^{2}+\beta \theta\right) c_{t+1}-\beta \theta c_{t+2}\right. \\
& \left.-\frac{1-\theta}{\sigma}\left((1-\beta \theta)\left(r_{t}-\pi_{t+1}\right)-\epsilon_{t}^{b}+(1+\beta \theta) \epsilon_{t+1}^{b}-\beta \theta \epsilon_{t+2}^{b}\right)\right\} \\
q_{t} & =-\left(r_{t}-E_{t} \pi_{t+1}\right)+\frac{1}{1-\delta+\bar{R}^{k}}\left\{(1-\delta) E_{t} q_{t+1}+\bar{R}^{k} E_{t} r_{t+1}^{k}\right\}+\eta_{t}^{q} \\
i_{t} & =\frac{1}{1+\beta} E_{t}\left\{i_{t-1}+\beta i_{t+1}+\zeta q_{t}+\beta\left(\epsilon_{t+1}^{i}-\epsilon_{t}^{i}\right)\right\} \\
k_{t} & =(1-\delta) k_{t-1}+\delta i_{t} \\
u_{t} & =\psi r_{t}^{k} \\
l_{t} & =-w_{t}+r_{t}^{k}+u_{t}+k_{t-1}, \\
y_{t} & =c_{y} c_{t}+g_{y} \epsilon_{t}^{g}+\delta k_{y} i_{t}+\bar{R}^{k} k_{y} u_{t} \\
y_{t} & =\phi\left[\epsilon_{t}^{a}+\alpha\left(u_{t}+k_{t-1}\right)+(1-\alpha) l_{t}\right] \\
w_{t} & =\frac{1}{1+\beta} E_{t}\left\{\beta w_{t+1}+w_{t-1}+\beta \pi_{t+1}-\left(1+\beta \gamma_{w}\right) \pi_{t}+\gamma_{w} \pi_{t-1}\right. \\
& -\frac{\lambda_{w}\left(1-\beta \xi_{w}\right)\left(1-\xi_{w}\right)}{\left(\lambda_{w}+\left(1+\lambda_{w}\right) \chi\right) \xi_{w}}\left(w_{t}-\chi l_{t}-\epsilon_{t}^{L}+\frac{\beta \theta}{1-\beta \theta}\left(\epsilon_{t}^{b}-\epsilon_{t+1}^{b}\right)-\eta_{t}^{w}\right. \\
& \left.\left.-\frac{\sigma}{(1-\theta)(1-\beta \theta)}\left(\left(1+\beta \theta^{2}\right) c_{t}-\theta c_{t-1}-\beta \theta c_{t+1}\right)\right)\right\} \\
\pi_{t}= & \frac{1}{1+\beta \gamma_{p}}\left\{\beta E_{t} \pi_{t+1}+\gamma_{p} \pi_{t-1}+\frac{\left(1-\beta \xi_{p}\right)\left(1-\xi_{p}\right)}{\xi_{p}}\left(\alpha r_{t}^{k}+(1-\alpha) w_{t}-\epsilon_{t}^{a}+\eta_{t}^{p}\right)\right\}
\end{aligned}
$$

As shown in Onatski and N. Williams (2004), equation (32) corrects a slight error in SW due to the capital utilization costs, which enter as the final term.

In addition, there are ten equations for the shock processes, six of which, 
$\left\{\epsilon_{t}^{a}, \epsilon_{t}^{\pi}, \epsilon_{t}^{b}, \epsilon_{t}^{g}, \epsilon_{t}^{l}, \epsilon_{t}^{i}\right\}$, follow $\mathrm{AR}(1)$ processes of the form:

$$
\epsilon_{t}^{x}=\rho_{x} \epsilon_{t-1}^{x}+\nu_{t}^{x},
$$

where $\nu_{t}^{x}$ is a mean zero innovation with variance $\sigma_{x}^{2}$. The remaining four shocks, $\left\{\eta_{t}^{p}, \eta_{t}^{q}, \eta_{t}^{r}, \eta_{t}^{w}\right\}$, are assumed to be i.i.d. with mean zero and variance $\sigma_{x}^{2}$. The innovations are assumed to have zero contemporaneous correlation.

The full model also includes counterparts to equations (26)-(33) that describe the loglinearized equations for the flexible-price allocation. In these equations, the shocks $\eta_{p}, \eta_{q}$, and $\eta_{w}$ are set to zero, as is the inflation rate. The nominal interest rate is replaced by the flexible-price real interest rate, $r_{t}^{*}$. This yields nine equations and nine additional variables, $\left\{c_{t}^{*}, i_{t}^{*}, y_{t}^{*}, w_{t}^{*}, l_{t}^{*}, q_{t}^{*}, r_{t}^{*}, r_{t}^{k *}, k_{t}^{*}\right\}$, where the asterisk superscript denotes the flexible-price value of the variable.

We close the model by including the linearized counterpart to the policy rule:

$$
\begin{aligned}
r_{t}= & r_{i} r_{t-1}+\left(1-r_{i}\right)\left(\bar{\pi}_{t}+r_{\pi}\left(\pi_{t-1}-\pi_{t-1}^{*}\right)+r_{y}\left(y_{t-1}-y_{t-1}^{*}\right)\right) \\
& +r_{\Delta \pi}\left(\pi_{t}-\pi_{t-1}\right)+r_{\Delta y}\left(y_{t}-y_{t}^{*}-\left(y_{t-1}-y_{t-1}^{*}\right)\right)+\eta_{t}^{r} .
\end{aligned}
$$

\section{B.2 Model with Monetary Frictions}

Here we note the modifications to the expressions above when we consider the model with monetary frictions. Linearizing (21) gives:

$-\kappa m_{t}+\epsilon_{t}^{m}=\frac{\bar{R}}{\bar{R}-1} r_{t}+\frac{\sigma}{(1-\theta)(1-\beta \theta)}\left(\left(1+\beta \theta^{2}\right) c_{t}-\theta c_{t-1}-\beta \theta E_{t} c_{t+1}\right)-\frac{\beta \theta}{1-\beta \theta}\left(\epsilon_{t}^{b}-E_{t} \epsilon_{t+1}^{b}\right)$

where $m_{t}$ is the log-deviation of real cash balances. Here $\bar{R}$ is the steady-state gross nominal rate which satisfies $\bar{R}=1+\bar{R}^{k}-\delta$. Linearizing (22) we see that we replace (31) with:

$$
l_{t}=-w_{t}-r_{t}+r_{t}^{k}+z_{t}+k_{t-1}
$$

Linearizing (23) we see that we replace (36) with:

$$
\pi_{t}=\frac{1}{1+\beta \gamma_{p}}\left\{\beta E_{t} \pi_{t+1}+\gamma_{p} \pi_{t-1}+\frac{\left(1-\beta \xi_{p}\right)\left(1-\xi_{p}\right)}{\xi_{p}}\left(\alpha r_{t}^{k}+(1-\alpha)\left(w_{t}+r_{t}\right)-\epsilon_{t}^{a}+\eta_{t}^{p}\right)\right\} .
$$




\section{Estimation Details and Results}

\section{C.1 Specification of the Priors}

Table 6 reports the details of the specification of the prior for the model. ${ }^{62}$ For the parameters of the shock processes, where we had little guidance from the literature, we set relatively loose priors. For the standard deviations, we used gamma distributions with standard deviations equal to the means. We gauged the relative magnitudes of the shocks from Onatski and N. Williams (2004) and SW. For all but one persistence parameter, we used a wide beta distribution. The exception was the inflation objective shock. Since it and the interest rate shock enter additively in the policy rule (37), a tighter prior is necessary to distinguish between them. For the structural parameters, we chose the parameters of the distributions to cover the range of estimates we found in the literature with reasonably high probability.

\section{C.2 Computation of the Posterior}

As in SW, we first look for a parameter vector which maximizes the posterior mode, given our prior and the likelihood based on the data. We took great efforts to explore the parameter space sufficiently to locate a global maximum. In particular, we sampled 200 values from the prior distribution, and used these as starting values for Chris Sims's optimization algorithms designed to avoid common problems with likelihood functions (available on his web page). We re-ran it in combination with a standard hill-climber algorithm until it settled on the maximal value. We used the resulting mode as the starting point for our MCMC sampling.

We then sample from the posterior distribution using a Metropolis-Hastings Markov chain Monte Carlo (MCMC) algorithm in order to make small sample inferences about the parameters. We sampled 10 separate chains for 45,000 periods each, discarding the first 15,000 periods. Thus we were left with 300,000 points from the posterior distribution. In order to assess convergence of the Markov chains, we use the potential scale reduction statistic described by Gelman, Carlin, Stern, and Rubin (2004) which gave clear indications of convergence for all the parameters.

\section{C.3 Estimation Results for the Shocks and the Monetary Model}

The text reports the estimation results for the structural parameters. Table 7 reports the estimates of the parameters for the shock processes. Figure 8 plots the prior and posterior distributions for the parameters describing the shock processes. Our prior insures that $\sigma_{r}$ never hits zero, but its modal value is only $4 \times 10^{-6}$. Except for the investment shock, the $\mathrm{AR}(1)$ shocks are highly persistent, with the inflation objective shock in particular being nearly a unit root process.

\footnotetext{
${ }^{62}$ For a brief survey of the literature on specification of priors, see Onatski and N. Williams (2004). This survey includes studies focusing on real models (such as King and Rebelo (1999) and Boldrin, Christiano, and Fisher (2001)) as well as papers focusing on monetary policy in smaller models (such as Rotemberg and Woodford (1997), Judd and Rudebusch (1998), Sack (1998)).
} 
Table 6: Specification of Priors

\begin{tabular}{lllrr}
\hline \hline Parameter & Distribution & Mean & Std Dev \\
\hline$\zeta$ & Investment adjustment costs & Normal & 0.5 & 0.2 \\
$\sigma$ & Consumption utility & Normal & 2 & 0.5 \\
$\theta$ & Consumption habit & Beta & 0.7 & 0.15 \\
$\chi$ & Labor utility & Normal & 1.2 & 0.5 \\
$\phi-1$ & Fixed cost-1 & Gamma & 0.075 & 0.0125 \\
$\psi^{-1}$ & Capital utilization costs & Log Normal & 6.4 & 5 \\
$\xi_{w}$ & Calvo wages & Beta & 0.375 & 0.1 \\
$\xi_{p}$ & Calvo prices & Beta & 0.375 & 0.1 \\
$\gamma_{w}$ & Wage indexation & Beta & 0.5 & 0.25 \\
$\gamma_{p}$ & Price indexation & Beta & 0.5 & 0.25 \\
\hline$r_{\pi}$ & Policy, lagged inflation & Normal & 2 & 0.5 \\
$r_{\Delta \pi}$ & Policy, change in $\pi$ & Normal & 0.2 & 0.1 \\
$r_{i}$ & Policy, lagged interest rate & Normal & 1 & 0.15 \\
$r_{y}$ & Policy, lagged output gap & Gamma & 0.25 & 0.25 \\
$r_{\Delta y}$ & Policy, change in gap & Gamma & 0.25 & 0.25 \\
$\sigma_{a}$ & Productivity & Gamma & 0.6 & 0.6 \\
$\sigma_{\pi}$ & Inflation objective & Gamma & 0.1 & 0.1 \\
$\sigma_{b}$ & Preference & Gamma & 0.3 & 0.3 \\
$\sigma_{g}$ & Govt. spending & Gamma & 0.3 & 0.3 \\
$\sigma_{l}$ & Labor supply & Gamma & 3 & 3 \\
$\sigma_{i}$ & Investment & Gamma & 0.1 & 0.1 \\
$\sigma_{r}$ & Interest rate & Gamma & 0.1 & 0.1 \\
$\sigma_{q}$ & External finance premium & Gamma & 5 & 5 \\
$\sigma_{p}$ & Price markup & Gamma & 0.2 & 0.2 \\
$\sigma_{w}$ & Wage markup & Gamma & 0.2 & 0.2 \\
\hline$\rho_{a}$ & Productivity & Beta & 0.5 & 0.25 \\
$\rho_{\pi}$ & Inflation objective & Beta & 0.85 & 0.1 \\
$\rho_{b}$ & Preference & Beta & 0.5 & 0.25 \\
$\rho_{g}$ & Government spending & Beta & 0.5 & 0.25 \\
$\rho_{l}$ & Labor supply & Beta & 0.5 & 0.25 \\
$\rho_{i}$ & Investment & & & \\
\hline \hline & & Gara & & \\
\hline
\end{tabular}


Table 7: Estimation Results

\begin{tabular}{|c|c|c|c|c|}
\hline \multicolumn{2}{|c|}{ Parameter } & \multirow{2}{*}{$\begin{array}{c}\begin{array}{c}\text { Posterior } \\
\text { Mean }\end{array} \\
0.5949\end{array}$} & \multicolumn{2}{|c|}{$\begin{array}{c}\text { 90\% Probability } \\
\text { Interval }\end{array}$} \\
\hline$\overline{\sigma_{a}}$ & Productivity & & 0.5441 & 0.6490 \\
\hline$\sigma_{\pi}$ & Inflation objective & 0.1153 & 0.0916 & 0.1430 \\
\hline$\sigma_{b}$ & Preference & 0.1346 & 0.0739 & 0.2171 \\
\hline$\sigma_{g}$ & Govt. spending & 0.2873 & 0.2635 & $-\quad 0.3134$ \\
\hline$\sigma_{l}$ & Labor supply & 2.4625 & 1.8121 & 3.2219 \\
\hline$\sigma_{i}$ & Investment & 1.0625 & 0.8815 & $-\quad 1.2570$ \\
\hline$\sigma_{r}$ & Interest rate & 0.0001 & 0.0000 & 0.0000 \\
\hline$\sigma_{q}$ & External finance premium & 4.0198 & 2.5531 & 6.4477 \\
\hline$\sigma_{p}$ & Price markup & 0.2072 & 0.1812 & $-\quad 0.2363$ \\
\hline$\sigma_{w}$ & Wage markup & 0.3035 & 0.2743 & 0.3351 \\
\hline$\rho_{a}$ & Productivity & 0.9639 & 0.9467 & 0.9794 \\
\hline$\rho_{\pi}$ & Inflation objective & 0.9950 & 0.9871 & 0.9995 \\
\hline$\rho_{b}$ & Preference & 0.9397 & 0.8868 & 0.9835 \\
\hline$\rho_{g}$ & Govt. spending & 0.9443 & 0.9147 & 0.9710 \\
\hline$\rho_{l}$ & Labor supply & 0.9833 & 0.9652 & 0.9972 \\
\hline$\rho_{i}$ & Investment & 0.7170 & 0.5755 & 0.8356 \\
\hline$r_{\pi}$ & Policy, lagged inflation & 2.6951 & 2.1525 & 3.2813 \\
\hline$r_{\Delta \pi}$ & Policy, change in $\pi$ & 0.2637 & 0.1650 & 0.3612 \\
\hline$r_{i}$ & Policy, lagged interest rate & 0.8392 & 0.7817 & 0.8921 \\
\hline & Policy, lagged output gap & 0.0968 & 0.0086 & $-\quad 0.2417$ \\
\hline$r_{\Delta y}$ & Policy, change in gap & 0.5091 & 0.4077 & 0.6386 \\
\hline
\end{tabular}

Table 8 reports the estimates for the specification of the model with monetary frictions from Section 7.1.

\section{Optimal Policy}

Here we report the impulse responses to other shocks.

In response to positive shocks to wages and Tobin's Q, the optimal policy calls for a sharp increase in interest rates that causes a large decline in consumption. The contractionary policy response reduces the responses of wages. In contrast, the estimated policy rule accommodates the shocks to a greater degree and allows larger rises in wage inflation. The optimal policy response to a transitory shock to prices, however, is to do virtually nothing. The estimated policy rule reacts to the rise in inflation, sending real rates higher and reducing consumption and aggregate labor. 

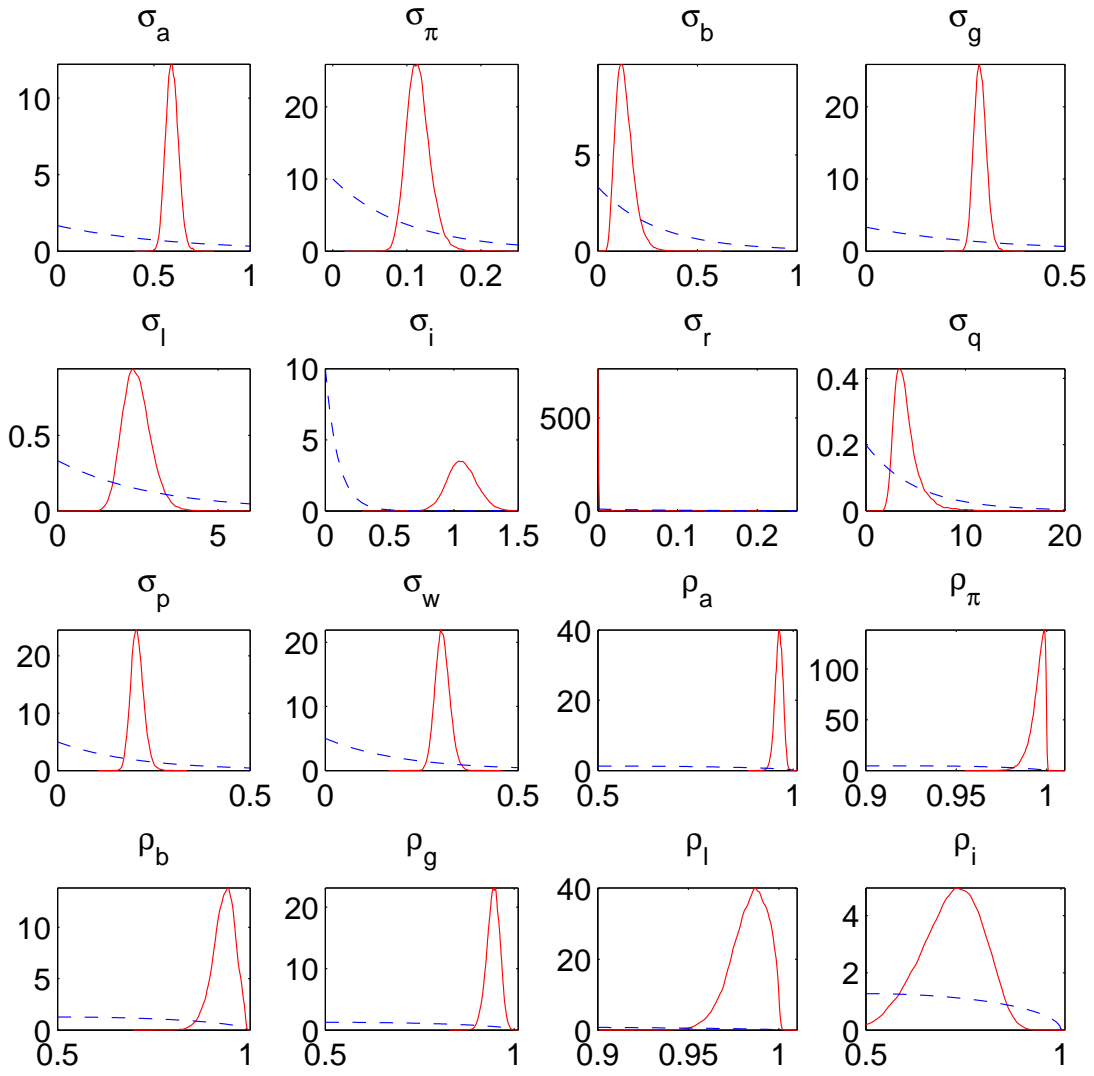

Figure 8: Estimated posterior distributions (red solid lines) and prior distributions (blue dashed) for the parameters describing the shock processes. 


\begin{tabular}{llcc}
\hline \hline & & & \\
Parameter & $\begin{array}{c}\text { Baseline } \\
\text { Specification }\end{array}$ & $\begin{array}{c}\text { Money } \\
\text { Frictions }\end{array}$ \\
\hline$\zeta$ & Investment adjustment & 0.5487 & 0.6119 \\
$\sigma$ & Consumption Utility & 2.0445 & 2.0433 \\
$\theta$ & Consumption Habit & 0.2935 & 0.3219 \\
$\chi$ & Labor Utility & 1.4051 & 1.6037 \\
$\kappa$ & Money Utility & - & 11.3822 \\
$\phi$ & Fixed cost & 1.0824 & 1.0805 \\
$\psi$ & Capital utilization & 0.1981 & 0.1769 \\
$\xi_{w}$ & Calvo wages & 0.8074 & 0.8123 \\
$\xi_{p}$ & Calvo prices & 0.8240 & 0.8335 \\
$\gamma_{w}$ & Wage indexation & 0.7734 & 0.8670 \\
$\gamma_{p}$ & Price indexation & 0.1159 & 0.1957 \\
\hline$\sigma_{a}$ & Productivity & 0.5942 & 0.5791 \\
$\sigma_{\pi}$ & Inflation objective & 0.1067 & 0.1030 \\
$\sigma_{b}$ & Preference & 0.1205 & 0.1256 \\
$\sigma_{g}$ & Govt. spending & 0.2847 & 0.2878 \\
$\sigma_{l}$ & Labor supply & 2.3217 & 2.3597 \\
$\sigma_{i}$ & Investment & 1.0349 & 1.0770 \\
$\sigma_{r}$ & Interest rate & 0.0000 & 0.0000 \\
$\sigma_{q}$ & External finance premium & 3.6781 & 3.3857 \\
$\sigma_{p}$ & Price markup & 0.2048 & 0.1653 \\
$\sigma_{w}$ & Wage markup & 0.2987 & 0.2931 \\
$\sigma_{m}$ & Money demand & - & 19.8955 \\
\hline$\rho_{a}$ & Productivity & 0.9611 & 0.9562 \\
$\rho_{\pi}$ & Inflation objective & 0.9944 & 0.9993 \\
$\rho_{b}$ & Preference & 0.9443 & 0.9392 \\
$\rho_{g}$ & Govt. spending & 0.9418 & 0.9486 \\
$\rho_{l}$ & Labor supply & 0.9803 & 0.9853 \\
$\rho_{i}$ & Investment & 0.7309 & 0.7221 \\
$\rho_{m}$ & Money demand & - & 0.9877 \\
\hline$r_{\pi}$ & Policy, lagged inflation & 2.7323 & 2.7974 \\
$r_{\Delta \pi}$ & Policy, change in $\pi$ & 0.2847 & 0.2586 \\
$r_{i}$ & Policy, lagged interest rate & 0.8318 & 0.8412 \\
$r_{y}$ & Policy, lagged output gap & 0.0001 & 0.0001 \\
$r_{\Delta y}$ & Policy, change in gap & 0.4811 & 0.5063 \\
\hline \hline & & & \\
\hline
\end{tabular}

Table 8: Mode estimates in the baseline specification and alternative specification with monetary frictions. 

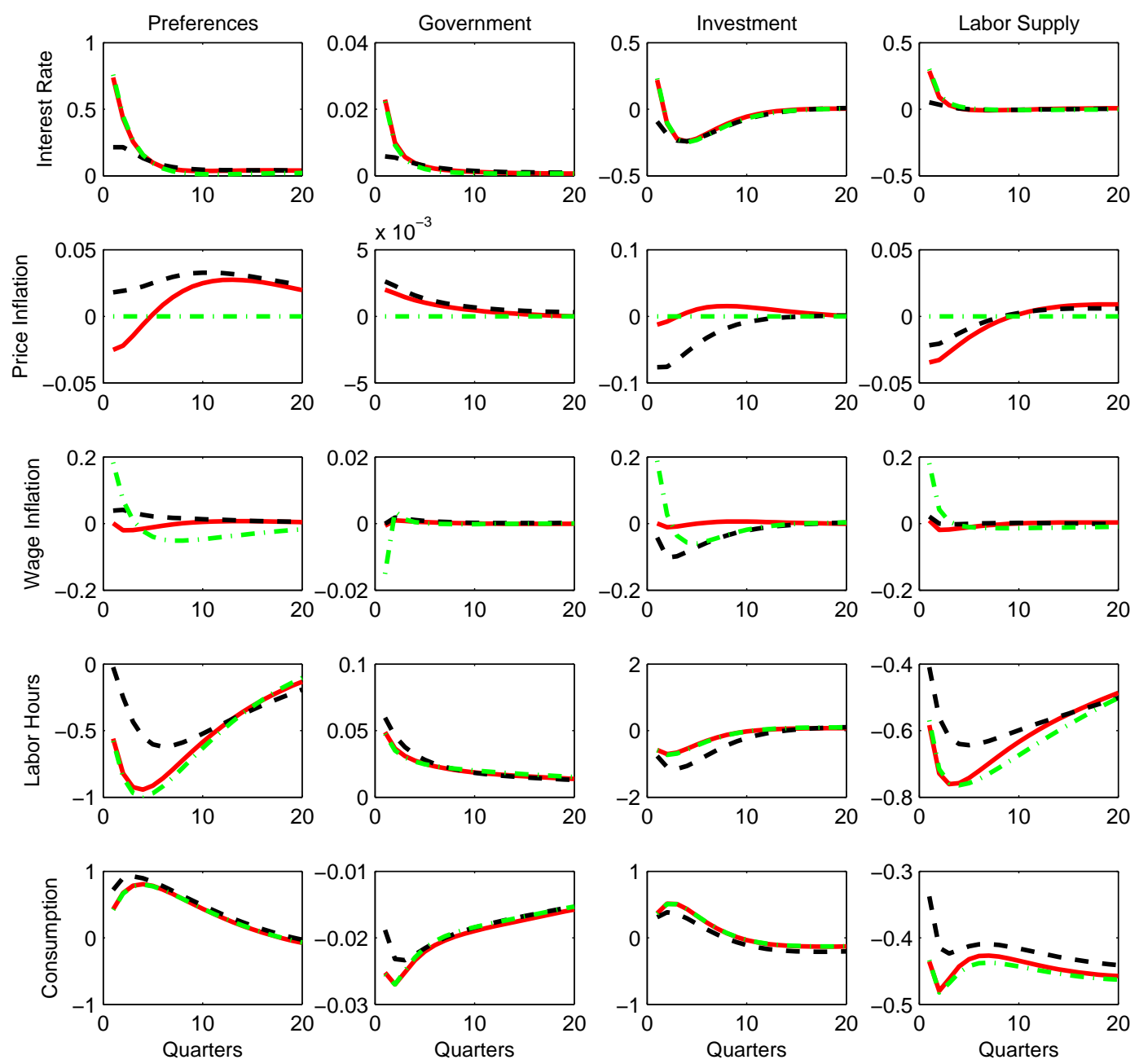

Figure 9: Impulse responses for one standard deviation shocks; optimal policy (red solid lines), estimated policy (black dashed lines), and flexible-wage and -price equilibrium (dash-dot green lines). 

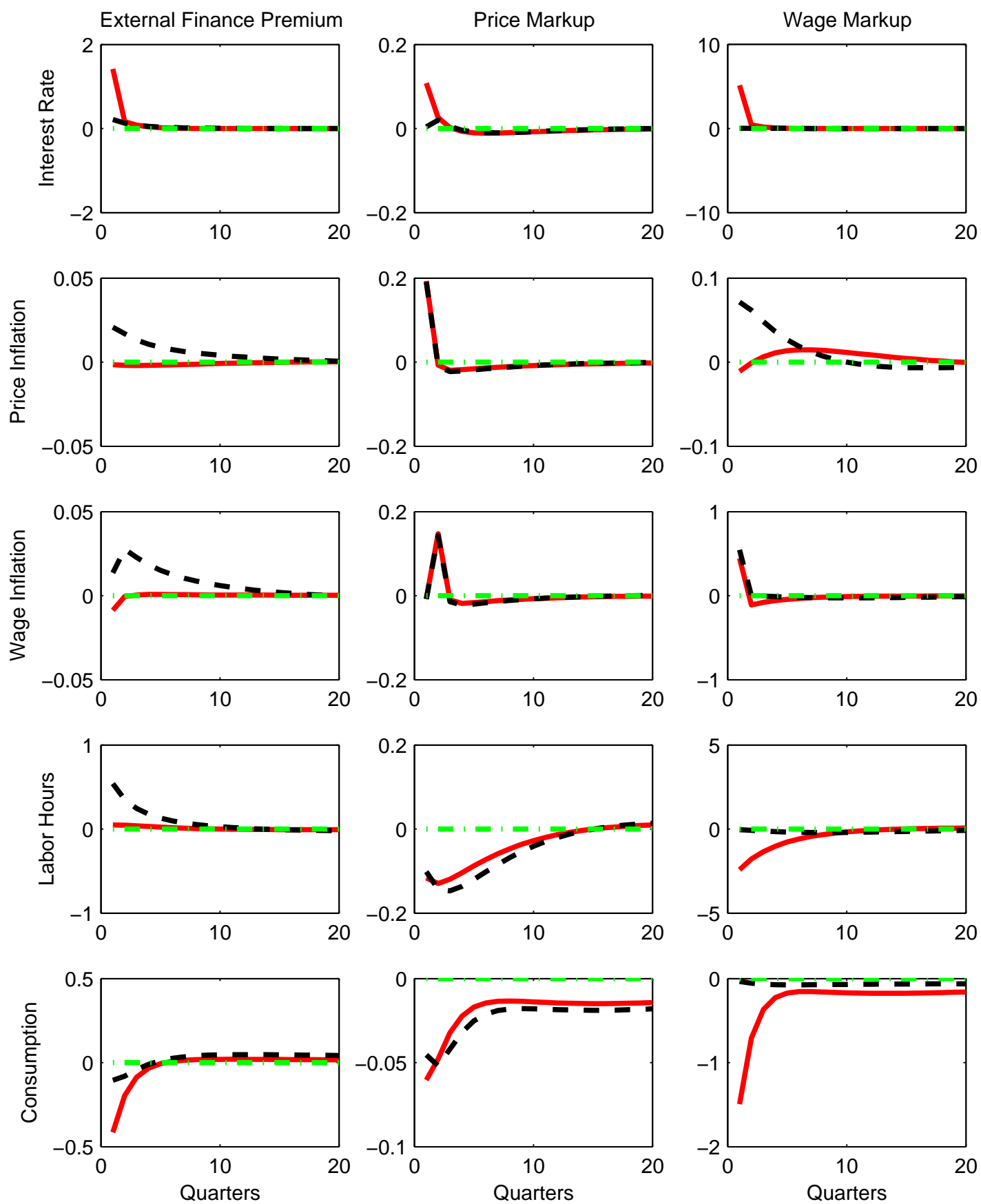

Figure 10: Impulse responses for one standard deviation shocks; optimal policy (red solid lines), estimated policy (black dashed lines), and flexible-wage and -price equilibrium (dash-dot green lines). 

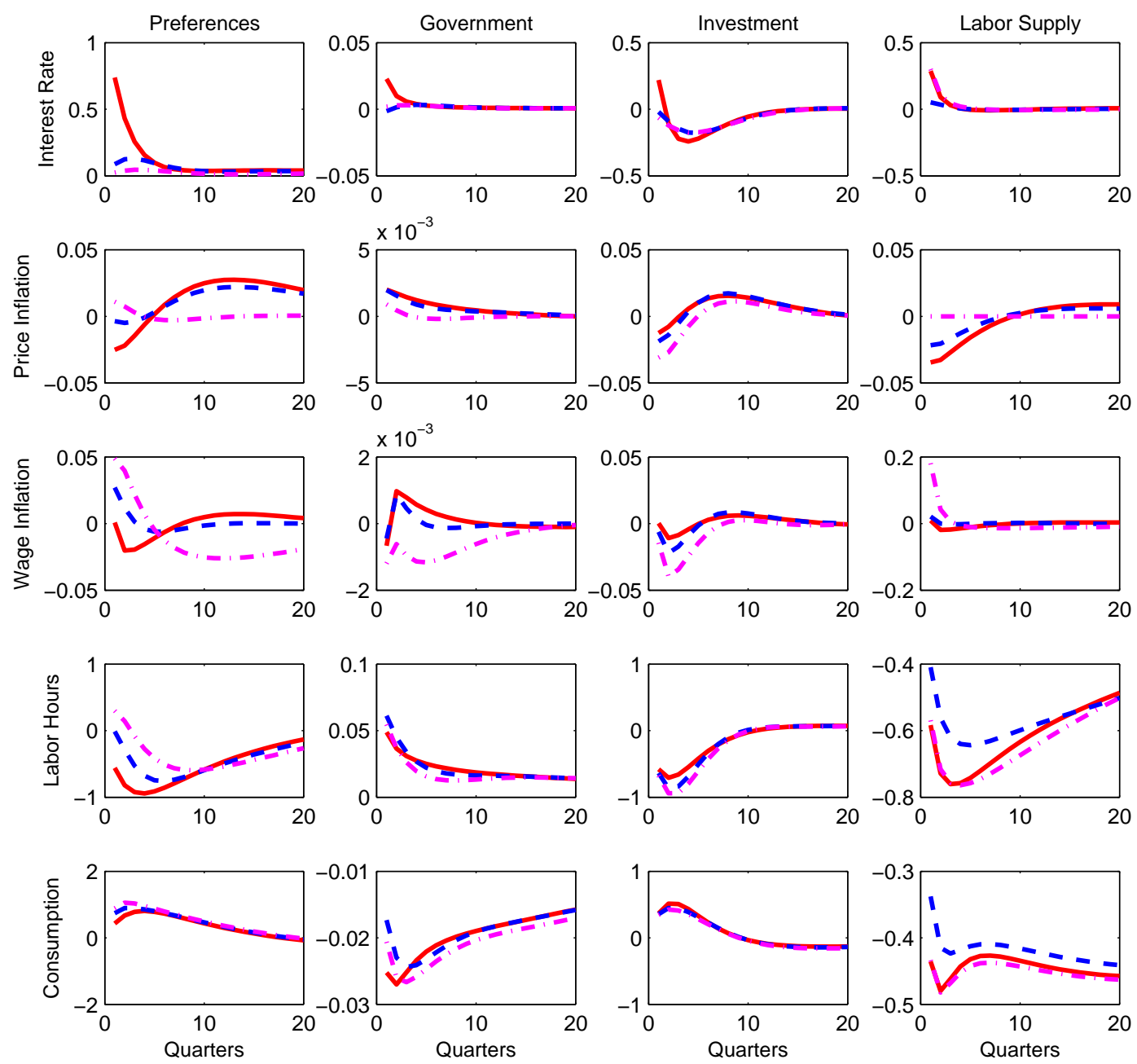

Figure 11: Impulse responses for one standard deviation shocks; optimal policy (red solid lines), optimized wage inflation policy rule (blue dashed lines), and the optimized price inflation rule (dash-dot magenta lines). 

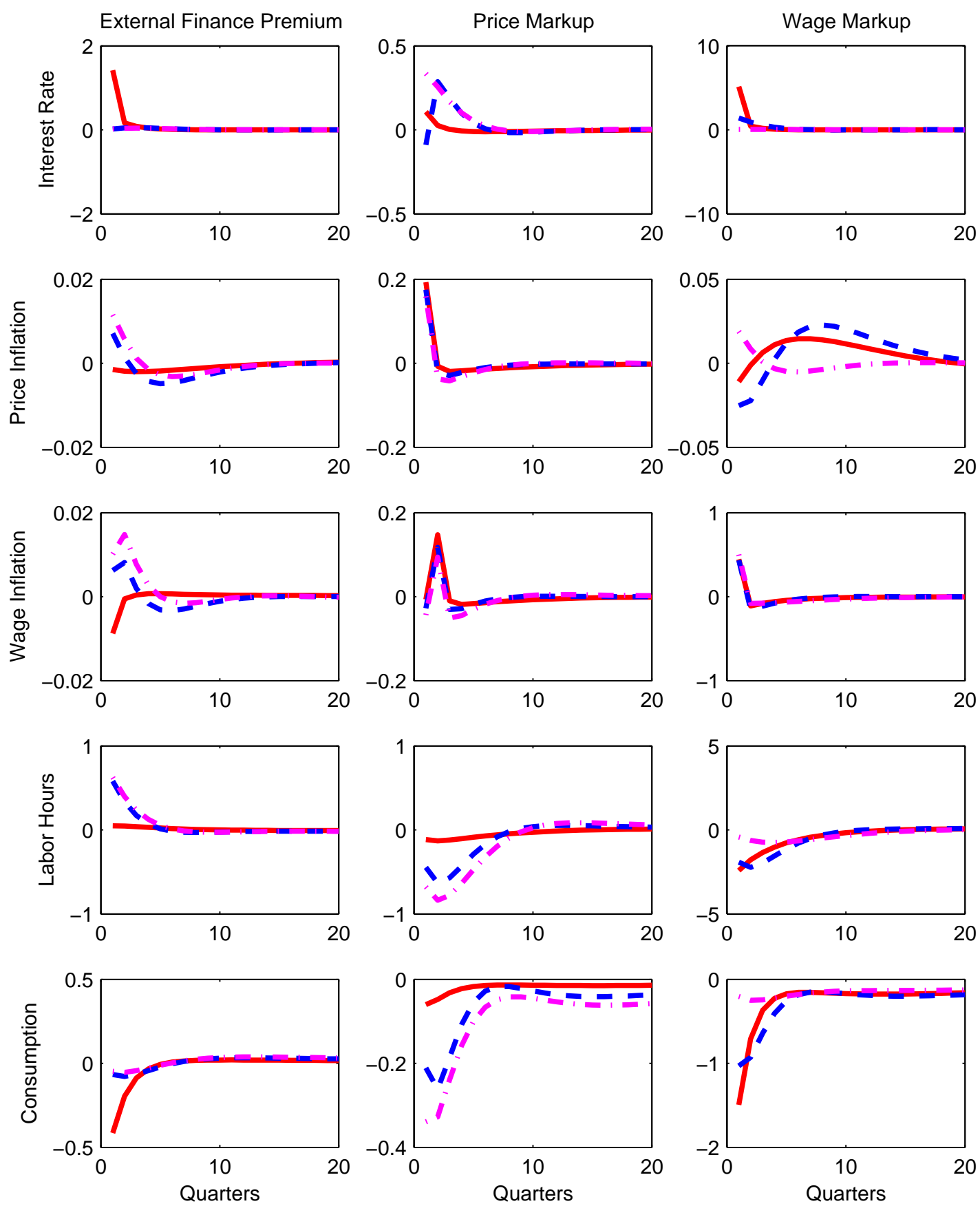

Figure 12: Impulse responses for one standard deviation shocks; optimal policy (red solid lines), optimized wage inflation policy rule (blue dashed lines), and the optimized price inflation rule (dash-dot magenta lines). 